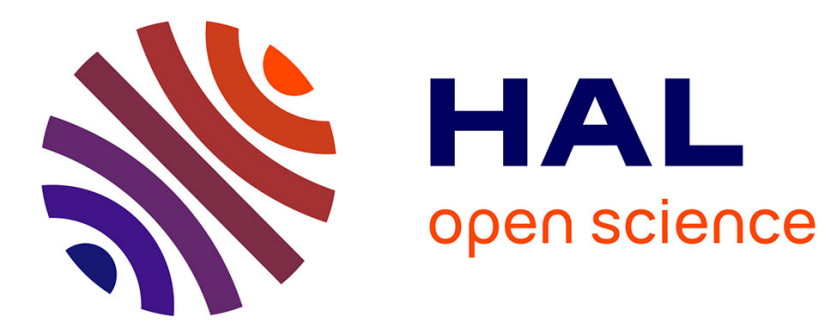

\title{
Soil moisture memory and West African monsoon predictability: artefact or reality?
}

H. Douville, S. Conil, S. Tyteca, Aurore Voldoire

\section{To cite this version:}

H. Douville, S. Conil, S. Tyteca, Aurore Voldoire. Soil moisture memory and West African monsoon predictability: artefact or reality?. Climate Dynamics, 2006, 28 (7-8), pp.723-742. 10.1007/s00382006-0207-8 . meteo-00181733

\section{HAL Id: meteo-00181733}

\section{https://hal-meteofrance.archives-ouvertes.fr/meteo-00181733}

Submitted on 6 Nov 2007

HAL is a multi-disciplinary open access archive for the deposit and dissemination of scientific research documents, whether they are published or not. The documents may come from teaching and research institutions in France or abroad, or from public or private research centers.
L'archive ouverte pluridisciplinaire HAL, est destinée au dépôt et à la diffusion de documents scientifiques de niveau recherche, publiés ou non, émanant des établissements d'enseignement et de recherche français ou étrangers, des laboratoires publics ou privés. 


\title{
Soil moisture memory and West African monsoon predictability: artefact or reality?
}

\author{
H. DOUVILLE, S. CONIL, S. TYTECA, A. VOLDOIRE
}

Corresponding author address :

CNRM/GMGEC/UDC

42 av. G. Coriolis

31057 Toulouse Cedex 1 FRANCE

Tel : 0561079625

Fax : 0561079610

Email: herve.douville@meteo.fr 
Besides sea surface temperature (SST), soil moisture (SM) exhibits a significant memory and is likely to contribute to atmospheric predictability at the seasonal timescale. In this respect, West Africa was recently highlighted as a "hot spot" where the land-atmosphere coupling could play an important role, through the recycling of precipitation and the modulation of the meridional gradient of moist static energy. Particularly intriguing is the observed relationship between summer monsoon rainfall over Sahel and the previous second rainy season over the Guinean Coast, suggesting the possibility of a soil moisture memory beyond the seasonal timescale. The present study is aimed at revisiting this question through a detailed analysis of the instrumental record and a set of numerical sensitivity experiments. Three ensembles of global atmospheric simulations have been designed to assess the relative influence of SST and SM boundary conditions on the West African monsoon predictability over the 1986-1995 period. On the one hand, the results indicate that SM contributes to rainfall predictability at the end and just after the rainy season over the Sahel, through a positive soil-precipitation feedback that is consistent with the "hot spot" hypothesis. On the other hand, SM memory decreases very rapidly during the dry season and does not contribute to the predictability of the all-summer monsoon rainfall. Though possibly model dependent, this conclusion is reinforced by the statistical analysis of the summer monsoon rainfall variability over the Sahel and its link with tropical SSTs. Our results indeed suggest that the apparent relationship with the previous second rainy season over the Guinean Coast is mainly an artefact of rainfall teleconnections with tropical modes of SST variability both at interannual and multi-decadal timescales. 


\section{Introduction}

Long-range forecasting of West African summer monsoon precipitation is a major challenge, especially in subsaharan countries whose dense populations and agrarian economies are very sensitive to any deficit in the June to September rainy season. Both statistical and dynamical methods have been proposed, which are all based on the assumption that the atmospheric variability is influenced on the seasonal timescale by slowly varying lower boundary forcings (Shukla 1998, Trenberth et al. 1998). While dynamical predictions rely on the explicit simulation of major atmospheric processes, it is still unclear that they lead to better estimations of seasonal precipitation anomalies on the regional scale (Folland et al. 1991, Garric et al. 2002). Most studies have emphasized the sensitivity of the African monsoon to global and regional patterns of sea surface temperature (SST) anomalies (Lamb 1978, Folland et al. 1986, Rowell et al. 1995, Janicot et al. 2001, Giannini et al. 2003). During the past decade, empirical statistical methods have been proposed to predict regional monsoon precipitation from SST predictors such as the time coefficients of global empirical orthogonal functions or SST indices averaged over selected domains (Folland et al. 1991, Landsea et al. 1993, Ward 1998). More recently, dynamical predictability studies have been conducted, based on several atmospheric general circulation models (GCMs) forced by observed SST anomalies or fully coupled to oceanic GCMs (Palmer et al. 2004). While the multi-model ensemble technique has shown a general improvement compared to single-model forecasts (Doblas-Reyes et al. 2005), prediction scores are still poor over West Africa, in keeping with former potential predictability studies suggesting that only a limited fraction of West African precipitation variability could be explained by SST anomalies (Rowell 1998).

Given this major obstacle, it is particularly important to look for other potential sources of seasonal predictability than ocean initial conditions. Besides SSTs, land surface variability is also likely to exhibit a significant memory, and therefore to contribute to climate predictability, at the monthly to multi-decadal timescales. Numerical sensitivity studies have first emphasized the possible influence of vegetation on North African climate through a positive surface albedo feedback onto precipitation (Charney et al. 1977). While climate-vegetation interaction is still believed to amplify the multi-decadal variability of rainfall in the Sahel (Wang et al. 2004), it is still unclear how it could exert a strong influence at the interannual timescale. In this respect, soil moisture (SM) is a more serious candidate. SM memory is controlled by the seasonality of the atmospheric state, the dependence of evaporation on SM, the variation of runoff with SM and by the coupling between SM and the atmosphere. Wu and Dickinson (2004) have quantified the timescales over which these factors act. SM memory is short within the Tropics and increases with latitude (Manabe and Delworth 1990). It increases with depth and varies with 
season, but it is relatively longer in arid regions. Furthermore SM memory can be much longer in dry conditions than in wet cases in warm climates (Wu and Dickinson 2004), but the key question is to know whether SM anomalies effectively translate into significant surface latent heat flux anomalies beyond a few days or weeks. Given the lack of direct observation of SM and surface turbulent fluxes at the regional scale, this question has been mainly adressed with numerical models. Many experiments based on idealised, modelled or analysed SM boundary conditions have suggested a potential contribution of SM to climate variability and predictability, particularly in boreal summer mid-latitudes (Manabe and Delworth 1990, Koster et al. 2000, Douville 2004, Conil et al. 2006). Nevertheless, when it comes to assess the impact of SM initialization (Douville and Chauvin 2000, Dirmeyer 2005, Conil and Douville 2006), the limited persistence of SM anomalies, the possible drift at the land surface, and the sizeable noise component of atmospheric variability make it particularly difficult to enhance the actual seasonal prediction scores, except in years of large departure from the climatology at the start of boreal summer in the mid-latitudes.

The particular sensitivity of the West Africa monsoon to surface hydrology has been emphasized by both observational and numerical studies. Fontaine and Philippon (2000) underlined the influence of spring to summer evolution of SM through moist static energy gradients on the Sahelian monsoon rainfall. Further exploring this hypothesis and the preliminary study of Landsea et al. (1993), Philippon and Fontaine (2002) proposed a monsoon regulation mechanism by SM, whereby September to November (SON) rainfall of the previous year could influence, and be a predictor of, July to September (JJAS) Sahelian rainfall. This remote rather than local effect is not in contradiction with the results of Shinoda and Yamaguchi (2003) who showed that Sahelian root-zone SM does not act as a memory of rainfall anomaly into the following rainy season. Moving to numerical studies, Douville et al. (2001) found a significant SM-precipitation feedback over sub-Saharan Africa in ensembles of JJAS seasonal hindcasts. Looking specifically at the 1987 and 1988 summer seasons, Douville (2002) suggested that the relaxation of the Arpege-Climat atmospheric GCM towards monthly reanalyses of SM could lead to a better simulation of the monsoon rainfall contrast, but suggested that this improvement was not mainly due to a regional feedback, but rather to a remote effect of mid-latitude stationary waves. Moreover, by comparing the global impact of initial and boundary conditions of SM, Douville and Chauvin (2000) suggested that SM memory was generally too short in their model to contribute significantly to boreal summer predictability. Using a longer but less reliable SM climatology, Douville (2004) further explored this issue and concluded that initial SM anomalies could have a significant influence on the predictability of JJAS precipitation in the boreal mid-latitudes (especially North America), but a limited impact in the tropics. Koster et al. (2004) compared the degree of land-atmosphere coupling in several atmospheric GCMs and found that North America and sub-Saharan Africa were two "hot spots" of strong interaction. 
Note however that the focus of the study was on intraseasonal rather than interannual timescale. Therefore, this result does not mean necessarily that SM is effectively a source of seasonal predictability of African monsoon rainfall.

In summary, there are still many uncertainties regarding the contribution of SM to Sahelian monsoon rainfall predictability. There is also some confusion between local versus remote effects, and daily-to-weekly versus monthly-to-seasonal timescales. The aim of the present study is to clarify these issues by using both a statistical analysis of available monthly climatologies and an original set of numerical sensitivity experiments. It will be shown that the low sensitivity of JJAS Sahelian rainfall predictability to SM in our GCM is not in contradiction with the multi-model West African "hot spot" found by Koster et al. (2004) and with the apparent statistical (not physical !) relationship between the Sahelian and previous second Guinean rainy seasons highlighted by Philippon and Fontaine (2002). This relationship is briefly revisited in section 2 . The numerical sensitivity experiments and their results are described in section 3 . Section 4 is an attempt to reconcile the observational and numerical analyses. Section 5 summarizes the main findings and draws the conclusions.

\section{Observational evidence of soil moisture influence on the seasonal timescale}

\subsection{Data sets}

Several global or regional climatologies of precipitation can be used to study the interannual variability of the West African monsoon rainfall over the last few decades. While they do show some differences in the magnitude of the annual cycle and in multi-decadal trends, they exhibit robust and consistent annual and seasonal anomalies. In the present study, we use the recent $0.5^{\circ}$ by $0.5^{\circ}$ Climate Research Unit (CRU2, Mitchell and Jones 2005) climatology that provides global monthly mean precipitation from 1901 to 2002. Other products such as the former lower-resolution CRU climatology (Hulme et al. 1998) available at http://www.cru.uea.ac.uk or the Global Precipitation Center Climatology (GPCC, Beck et al. 2005) available at http://www.dwd.de/vasclimo have been also tested and lead to similar conclusions, but the need for a relatively long and high-resolution instrumental record has guided the choice of the CRU2 dataset. Note however that the original product has been interpolated onto the 128 by 64 horizontal grid of the Arpege-Climat model to enable a better comparison of simulated versus observed precipitation. Two rainfall indices will be used in the continuation of the study: a sub-Saharan or Sudan-Sahel rainfall index (SSR) and a Guinean Coast rainfall index (GCR) that have been averaged over $10^{\circ} \mathrm{N}-20^{\circ} \mathrm{N} / 20^{\circ} \mathrm{W}-40^{\circ} \mathrm{E}$ and $4^{\circ} \mathrm{N}-10^{\circ} \mathrm{N} / 15^{\circ} \mathrm{W}-10^{\circ} \mathrm{E}$ respectively. Their annual anomalies relative to the late $20^{\text {th }}$ century climatology are shown in Fig. 1 and illustrate the strong variability of West African 
rainfall at both interannual and multi-decadal timescales. Two SST indices will be also used to account for the main teleconnections between the West African monsoon and the tropical oceans: a Guinean Gulf index (GGT) in the eastern equatorial Atlantic $\left(5^{\circ} \mathrm{S}-5^{\circ} \mathrm{N} / 30^{\circ} \mathrm{W}-10^{\circ} \mathrm{E}\right)$ and the well-known Niño-3 SST index in the eastern equatorial Pacific $\left(5^{\circ} \mathrm{S}-5^{\circ} \mathrm{N} / 150^{\circ} \mathrm{W}-90^{\circ} \mathrm{W}\right)$. Global monthly SSTs are derived from the 1870-2002 HadSST.1 climatology (Rayner et al. 2003) and have been also interpolated onto the Arpege-Climat horizontal grid.

Given the lack of adequate in situ and satellite observations, more or less constrained land surface model outputs are generally used to validate or specify SM in GCMs. The present study takes advantage of phase 2 of the Global Soil Wetness Project (GSWP2, Dirmeyer et al. 2005) to derive a 10year $1^{\circ}$ by $1^{\circ}$ global SM reanalysis by driving the ISBA (Interaction Sol-Biosphère-Atmosphère, Douville 1998) land surface model with a combination of 3-hourly meteorological analyses and monthly precipitation, radiation and temperature climatologies (Decharme and Douville 2006). Note however that this climatology is not exactly the one which has been provided to the GSWP intercomparison project, but a slightly different one based on an alternative and presumably better precipitation forcing (P3 instead of B0 baseline product) and on a 2-layer rather than 3-layer soil hydrology, in keeping with the ISBA version used in the Arpege-Climat GCM. This dataset can be compared with the multi-model GSWP2 reanalysis available at http://haneda.tkl.iis.u-tokyo.ac.jp/gswp2 (based on a dozen of land surface models driven by the same atmospheric forcing except the B0 rather than $\mathrm{P} 3$ precipitation) and with the ERA40 reanalysis in which an "on-line" sequential assimilation of screen-level temperature and humidity is used to analyse SM in the European Center for Medium-range Weather Forecast model (Douville et al. 2000). Note that this alternative product is based on a totally different methodology than GSWP2 and therefore represents a fully independent dataset to assess uncertainties in monthly SM anomalies over West Africa.

Fig. 2 compares the monthly evolution of absolute SM anomalies over the previously defined Sudan-Sahel and Guinean Coast domains, despite the use of different soil parameters (including soil depth) in ISBA, ERA40 and the GSWP2 multi-model analysis. Obviously, ISBA is in close agreement not only with the multi-model product but also with ERA40, which gives us relative confidence in our SM climatology. The agreement is however better over sub-Saharan Africa than over the Guinean Coast, which can be attributed to the different size of the domains and the more complex seasonality of the Guinean Coast precipitation. Also shown in Fig. 2 are the associated monthly evaporation anomalies. Here again, the three products are consistent. Interestingly, they all indicate that SM anomalies are more persistent than evaporation anomalies, suggesting that SM memory might exist without significant signature on turbulent surface fluxes and low atmosphere variables. This result is expected given the fact that evaporation is only sensitive to SM over a limited range of soil wetness. The SM persistence 
found in our study is relatively consistent with the results of Shinoda and Yamaguchi (2003) based on a simple water balance model and on in situ observations, who showed that the typical timescale of the drying up of root-zone SM is approximately 1.5 months in the Sahel.

\subsection{Modes of interannual variability of West African monsoon rainfall}

A principal component analysis (PCA) had been applied to observed JJAS precipitation over West Africa $\left(0-25^{\circ} \mathrm{N}, 20^{\circ} \mathrm{W}-25^{\circ} \mathrm{E}\right)$ based on filtered seasonal anomalies from CRU2 over the $20^{\text {th }}$ century. The filtering is based on a digital high-pass filter with a 10-year frequency cutoff and a Dolph-Chebyshev convergence window. Note that the period of analysis is in fact reduced to the 1911-1992 period since the loss of 10 years at the beginning and the end of the CRU2 timeseries is the price to be paid for the filtering. The resulting leading spatial patterns (EOFs) are shown in Fig. 3. Compared to the results obtained with raw data (not shown), the filtering leads to a permutation of the first two EOFs. The first EOF ( $25 \%$ of total variance) is a dipole pattern between sub-Saharan Africa and the Guinean Coast, while the second EOF (19\% of total variance) shows a homogeneous anomaly pattern encompassing both regions. EOF 3 and 4 account for a much smaller fraction of the JJAS precipitation variability and, not surprisingly, reveal more complex geographical patterns.

Fig. 4 shows global correlation maps between the leading PCs and filtered JJAS SST anomalies. In keeping with the results of former studies (i.e. Giannini et al. 2003), EOF1 is related to the SST variability in the eastern tropical Atlantic. Warm SSTs in the Guinean Gulf are associated with a southward shift of the Inter-Tropical Convergence Zone (ITCZ) and therefore with a rainfall deficit (excess) over the Sahel (Guinean Coast). EOF2 mainly shows a strong connection with the El Niño Southern Oscillation (ENSO), as indicated by the significant correlations found in the tropical Pacific. Note again that multi-decadal variability has been removed from the precipitation and SST timeseries so that ENSO does not appear here as the main driver of the monsoon variability and the Indian Ocean influence is also partly suppressed though apparent in the SST correlations with EOF4.

Fig. 5a shows lead-lag correlations of the 4 principal components $(P C)$ in year 0 with monthly anomalies in SSR (as well as GCR for the first PC) from year -1 to year +1 . As expected from Fig. 3 , PCs 1 and 2 are significantly anticorrelated with SSR during the monsoon season in year 0 . The relative stability of the fraction of variance explained by each EOF is illustrated by Fig. 5b showing sliding correlations between JJAS SSR (as well as GCR for the first PC) and the PCs. The correlations with PC1 and PC2 remain significant over the whole $20^{\text {th }}$ century, even if the Atlantic mode (EOF1) shows an apparent weakening over the last three decades, in association with a strengthening of the ENSO mode (EOF2). This result is consistent with the conclusions of former studies (Janicot et al. 2001, Giannini et 
al. 2003). Also noticeable in Fig. 5a are the significant positive correlations of PC1 with SSR during the previous (year -1 ) and next (year +1 ) monsoon seasons. This biennial behaviour is also found when looking at the lead-lag correlations with monthly GCR (dashed line). In keeping with the dipole structure of EOF1, PC1 shows a strongly positive correlation with GCR in year 0 , but negative correlations before and after the central year, especially in JASO-1. The synchroneous correlation is very stable (dashed line in Fig. 5b), suggesting that the pattern of EOF1 is very robust. More importantly, the significant anticorrelation of PC1 with GCR in year -1 suggests that the magnitude of the second rainy season over the Guinean Coast could be a precursor of the next monsoon rainfall over the Sahel.

\subsection{Link between Guinean Coast and sub-Saharan precipitation}

This hypothesis is further explored in Fig. 6 showing correlation maps between JJAS SSR anomalies and grid-cell SON precipitation anomalies of the previous year over West, North and East Africa. When estimated from the raw seasonal precipitation timeseries (Fig. 6a), the results confirm that SON Guinean rainfall in year -1 is strongly correlated with JJAS SSR in year 0 , in keeping with the results of Philippon and Fontaine (2002) obtained over the 1968-1998 period. Removing a linear trend estimated over the whole instrumental record leads to a slight weakening of this relationship (Fig. 6b). Conversely, filtering the seasonal timeseries using the same high-pass filter as before leads to a dramatic collapse of the correlations (Fig. 6c), suggesting that the apparent inter-seasonal link between GCR and SSR is mainly due to multi-decadal variability.

This result is not surprising given the in-phase oscillations of the low-pass filtered SSR and GCR annual anomalies shown in Fig. 1. It is also confirmed by Fig. 7a showing lead-lag correlations between JJAS SSR and monthly GCR anomalies over a 3-year window. While the detrended timeseries (no high-pass filter) shows strongly positive correlations during SON-1 (as well as from August of year 0 to December of year +1$)$, the filtered timeseries shows a much weaker and hardly significant signal. There is also a slight seasonal shift in the peak of correlation during year -1 that changes from SON to JASO (July to October). This is confirmed by Fig. 6d showing a strengthening of the Guinean Coast correlations compared to Fig. 6c. Note also that the peak of lead correlations found in Fig. 7a is also found when looking at the CRU or GPCC precipitation climatologies (not shown). Finally, the robustness of the Guinean Coast precursor is illustrated in Fig. 7b showing sliding correlations between JASO-1 GCR and JJAS SSR. Except in the early decades of the $20^{\text {th }}$ century where the instrumental record is probably the most uncertain, the positive correlation is very stable and is always stronger for filtered versus unfiltered anomalies. 
This statistically robust relationship has been attributed to a remote SM influence by Philippon and Fontaine (2002). The proposed mechanism is that the Guinean Coast SM anomalies associated with the second rainy season are likely to persist during the dry season, to modulate the moist static energy gradients above the continent in March-April of year +1 , and thereby to influence the monsoon dynamics and the associated rainfall over the Sahel. Though physically based, this scenario seems very uncertain. It relies on a strong SM memory that is not confirmed by the SM reanalyses shown in Fig. 2, as well as on a significant atmospheric response to SM anomalies that is unlikely given the relatively small size of the Guinean Coast domain. Nevertheless, this issue has been further explored using the Arpege-Climat atmospheric GCM.

\section{Numerical sensitivity experiments with the Arpege-Climat model}

\subsection{Experiment design}

The GSWP2 project has offered the opportunity to produce a 10-year (1986-95) SM analysis that is fully consistent with the ISBA land surface model that is currently used in the Arpege-Climat model (Déqué et al. 1994, Douville and Chauvin 2000). It is therefore very natural to use this climatology to prescribe SM at the lower boundary conditions of the GCM, just as we do with SST. Several strategies can be used for this purpose, but the relaxation of deep SM towards the monthly mean ISBA outputs of GSWP2 is probably the most suitable technique to constrain the monthly SM evolution while keeping a realistic land surface feedback at higher frequencies (Douville 2003).

This methodology has been recently applied in ensembles of atmospheric simulations driven by observed monthly mean SSTs from the HadSST.1 climatology (Rayner et al. 2003). A detailed description of these experiments can be found in Conil et al. (2006). The control experiment, FF, is a 10member ensemble of September 1985 to December 1995 integrations starting from different initial conditions derived from a former model integration. The ISBA land surface model is here fully interactive with the atmosphere and is not nudged towards GSWP2. The ensemble technique allows us to isolate the fraction of the total variance that is forced by the SST boundary conditions using a simple 1-way ANOVA model (Von Storch and Zwiers 1999).

Two sensitivity experiments have been also performed using the same ensemble technique and the same initial conditions. The experiment design is summarized in Table 1. Experiment GG is similar to $\mathrm{FF}$, but includes the relaxation towards the GSWP2 monthly mean SM climatology obtained with ISBA. Experiment EE also includes the relaxation, but uses climatological rather than interannual SSTs. A last 
experiment, starting from GG integrations at the end of May and carrying on the integrations without relaxation, was also performed to assess the impact of SM initialization on JJAS hindcasts but is not discussed in the present study given the lack of response over West Africa. None of the experiments deals with the impact of atmospheric initialization, which is however important during the first month of the integration. The objective here is not to replicate the design of operational long-range dynamical forecasts, but rather to compare the relevance of SST and SM boundary conditions at the seasonal timescale.

\subsection{Mean annual cycle}

Before looking at the impact of SM on seasonal variability and predictability, it is important to look at the mean climate, especially for variables like precipitation whose skewed distribution favours a link between variability and mean state. The aim here is just to illustrate that the Arpege-Climat model performs a reasonable simulation of the annual cycle of the West African monsoon and that the SM relaxation does not have a dramatic impact on the mean climate. More details about the model climatology and variability in this region can be found in Joly et al. (2006). A global evaluation of the EE, FF and GG experiments is available in a companion study by Conil et al. (2006).

Like in most areas, the relaxation of Arpege-Climat towards the ISBA-derived GSWP2 SM climatology has a limited impact on the West African model climatology. This can be explained by the limited SM biases found in the control experiment over both sub-Saharan Africa and the Guinean Coast compared to the GSWP2 climatology (Fig. 8a,b). Also shown in Fig. 8 is the mean annual cycle of SM in the ERA40 reanalysis over the 1958-2001 period, which is very different from GSWP2. Despite the relative agreement between ERA40 and GSWP2 noted in Fig. 2 as far as interannual variability is concerned, this large difference is consistent with the GSWP2 intercomparison showing that the model spread is much stronger for absolute SM than for SM variations. ERA40 considers uniform rather than variable soil properties and includes a relaxation towards a climatology to avoid a spurious drift of SM. These remarks can explain the lack of contrast between Sahel and the Guinean Coast as well as the weaker magnitude of the annual cycle in ERA40 compared to GSWP2. ERA40 is also likely to underestimate the interannual variability of SM (Ferranti and Viterbo 2006), as is suggested by the monthly SM anomalies shown in Fig. 2.

Fig. 8a and $\mathrm{b}$ also show that the sensitivity experiment, GG, is very close to GSWP2. While this result demonstrates the efficiency of the nudging technique to constrain SM in the Arpege-Climat model, it is important to note that it does not mean that surface evaporation is also fully constrained. This is illustrated by Fig. $8 \mathrm{c}$ and $d$ that compare the annual cycle of simulated evaporation with the ERA40 and 
GSWP2 climatologies. Whereas there are significant differences between the ERA40 and GSWP2 analyses, the Arpege-Climat model tends to overestimate surface evaporation, especially over Sudan and Sahel, both in FF and GG. There is only a limited sensitivity to the SM relaxation, which is qualitatively consistent with the SM differences shown in Fig. 8a and b. The gap between GG and GSWP2 indicates that Arpege-Climat has significant errors in the atmospheric variables that control surface evaporation. It suggests in particular a dry bias in the boundary layer. Note however that the goal of the present study is to assess the model sensitivity to interannual anomalies of SM. The positive bias in surface evaporation found in the Arpege-Climat model is not necessarily a major obstacle for this purpose.

Finally, Fig. $8 \mathrm{e}$ and $\mathrm{f}$ show the mean annual cycle of the regional SSR and GCR rainfall indices. Compared to the CRU2 climatology and to the GSWP2 precipitation forcing, the Arpege-Climat model shows a reasonable simulation of both magnitude and timing of the monsoon. Note however that the length of the rainy season is overestimated over sub-Saharan Africa. It is better simulated over the Guinean Coast where the model is even able to capture the bimodal rainfall distribution (first and second rainy seasons) that is found in the original high-resolution CRU2 dataset, but is here obscured by the interpolation onto the Arpege-Climat horizontal grid. Comparing GG to FF reveals only a slight increase in summer rainfall over Sudan and Sahel, in keeping with the evaporation response. This limited sensitivity of mean precipitation is important to keep in mind. The key question is indeed to know whether the relaxation has an impact on precipitation variability and predictability. If such an impact does exist, it will not be an artefact of a change in mean climate but a real direct response to the damping of internal SM variability (Douville 2003).

\subsection{ANOVA}

In order to first quantify the effects of SM and SST on potential climate predictability, we make use of a one-way analysis of variance (ANOVA) for which the previously described simulations were designed. The ANOVA is a powerful tool allowing the decomposition of the total variance into an internal and an externally-forced (SST and/or SM) component: $\mathrm{St}=\mathrm{Si}+\mathrm{Se}$. The ratio of externally-forced versus total variability is defined as potential predictability: $\mathrm{PP}=\mathrm{Se} / \mathrm{St}$. Details on the methodology and its underlying hypotheses can be found in Von Storch and Zwiers (1999).

Fig. 9 shows the annual cycle of total variability and potential predictability of surface evaporation, zonally averaged between $20^{\circ} \mathrm{W}$ and $25^{\circ} \mathrm{E}$ over West Africa. In the control experiment (Fig. 9a), the standard deviation of surface evaporation shows several maxima, including expected ones at the end of the rainy season(s) in equatorial and sub-Saharan latitudes, but also unexpected ones over North Africa 
due to an overestimated northward migration of the ITCZ in summer. This unrealistic maximum is not suppressed by the relaxation towards GSWP2, but the sensitivity experiments (Fig. 9c,e) show a general weakening of the evaporation variability that is consistent with the damping of internal SM variability, as well as of SST variability in EE. Looking back at the control experiment (Fig. 9b), the potential preditability of land surface evaporation is very low north of $10^{\circ} \mathrm{N}$. The maximum predictability (30 to $40 \%$ ) is found between the two rainy seasons at equatorial latitudes, and during the dry season over the Guinean Coast. The relaxation of SM towards GSWP2 has a strong impact in experiment GG (Fig. 9d), that shows increased predictability at most latitudes and in most seasons. Nevertheless, the predictability remains relatively low during the rainy season, especially over Sudan and Sahel where a clear minima appears during the summer monsoon. This minima is also found in EE, which confirms that prescribing monthly SM anomalies is not sufficient to control the interannual variability of surface evaporation in the Arpege-Climat model. Surface evaporation also depends on atmospheric variables whose potential predictability can be very low. The main exception found at sub-Saharan latitudes in Fig. $9 d$ and $f$ is the end of the rainy season, when the magnitude of the SM anomalies is maximum.

Fig. 10 is similar to Fig. 9, but for precipitation. Total variability (Fig. 10a) shows the signature of the meridional migration of the ITCZ over West Africa and is not strongly reduced when SM is relaxed (Fig. 10c) and when SST variability is suppressed (Fig. 10e). This result suggests that the total variability of West African precipitation is dominated by the chaotic component - internal variability - of the climate system. This is confirmed by Fig. 10b showing that the potential predictability of precipitation related to the SST boundary forcing is very low in the control experiment. Significant predictability (above 20\%) is only found over the Guinean Coast, with relative minima at the beginning and the end of the rainy season. Comparing GG to FF does not reveal significant differences, indicating that SM has a negligible influence on the potential predictability of West African monsoon rainfall in the Arpege-Climat model. Experiment EE strengthens this conclusion, as indicated by the very low forcing of precipitation variability by SM when the SST variability is suppressed (Fig. 10f).

\subsection{Actual skill at the seasonal timescale}

We will now briefly quantify the ability of the model to reproduce the observed past rainfall variations, e.g. the skill of the model, by calculating the grid-cell temporal anomaly correlation coefficient (ACC) between observed (CRU2) and simulated anomalies of JJAS rainfall over West Africa. Many studies have suggested that such a skill is generally limited, not only outside the tropics, but also in various tropical regions such as West Africa (Garric et al. 2002, Doblas-Reyes et al. 2005, Guérémy et al. 2005). The current version of the Arpege-Climat model is not an exception and shows relatively poor 
scores in the control experiment, even if correlations exceed 40 to $50 \%$ over some limited areas including Central Sahel and the fringe of the Guinean Coast (Fig. 11b). Though estimated with only 10 years, these precipitation scores are relatively robust and show similar patterns in the GG sensitivity experiment (Fig. 11d). It is thus impossible to detect a significant impact of using more realistic SM boundary conditions on the actual predictability of JJAS monsoon rainfall over West Africa.

This result is consistent with the response of potential predictability and with the limited impact of SM relaxation on the actual predictability of surface evaporation (Fig. 11a and C). When evaluated against the GSWP2 climatology (i.e. the results of ISBA driven by the GSWP2 atmospheric forcing), the evaporation ACCs are not dramatically increased in GG versus FF, despite the use of "perfect" SM boundary conditions. This is due to the fact that surface evaporation is only partly controlled by SM. It also depends on the atmospheric demand (i.e. potential evaporation) and therefore on many physical processes (radiation, turbulence, moisture advection) whose predictability can be very low.

Looking at the additional sensitivity experiment with climatological SST (Fig. 11e) confirms this hypothesis. In this case, the actual predictability of surface evaporation is relatively strong over subSaharan Africa, due to the fact that this region is a transition zone between the wet Guinean Coast and the dry Sahara and thus the main area where SM variability is likely to exert a strong influence on surface evaporation. The correlations are even higher than in Fig. 11c, suggesting that the lack of SSTforced predictability of potential evaporation is indeed a major obstacle to translate the SM signal to the atmosphere in experiment GG. Note finally that, despite the use of climatological SSTs, EE shows a significant skill in JJAS precipitation (Fig. 11f) in the Sahelian area where the skill in surface evaporation is maximum (Fig. 11e). This result indicates that "perfect" SM boundary conditions can in theory contribute to precipitation predictability, but that this contribution remains in practice negligible for at least two reasons: first, the limited magnitude of the SM-forced variability compared to the SST-forced variability, and secondly, the limited ability of the model to capture the monsoon teleconnections with tropical SSTs (Joly et al. 2006). The situation is even worse when the GSWP2 climatology is used only to initialize SM at the end of May (not shown). In this case, the low sensitivity of the West African monsoon rainfall is reinforced by the limited persistence of the initial SM anomalies.

Given the difficulty to derive robust ACC scores over a limited 10-year period, Fig. 12 and 13 also show the year-by-year evolution of the simulated and observed climate anomalies after averaging the data over Sudan and Sahel $\left[10-20^{\circ} \mathrm{N} / 20^{\circ} \mathrm{W}-40^{\circ} \mathrm{E}\right]$. For the simulations, an indication of the spread is provided in addition to the ensemble mean anomalies. Fig. 12a,b,c compares the JJAS surface evaporation anomalies simulated in FF, GG and EE to the GSWP2 climatology. For each experiment, the ACC between "observed" and "predicted" ensemble mean anomalies is indicated. Not surprisingly, the ACC increases and the spread decreases from FF to GG. In keeping with Fig. 11, the ACC is even 
stronger in EE, but the spread is not reduced. When focusing on August to November (ASON), the interannual variability of evaporation and its sensitivity to prescribed SM boundary conditions are more pronounced, suggesting that SM recycling becomes more important at the end of the rainy season. Fig. 13 shows similar diagnostics for average JJAS and ASON precipitation over Sudan and Sahel. Like in Fig. 11, there is no evidence of improved seasonal anomalies in GG versus FF, even for individual years. The only noticeable result is the increase in ACC in EE, more pronounced in ASON than in JJAS. Note however that the signal shown by the EE ensemble mean rainfall anomalies remains very weak compared to the observed anomalies and to the model spread that is not dramatically reduced by the use of climatological SSTs.

\section{Discussion}

In summary, the Arpege-Climat model does not support the SM mechanism proposed by Philippon and Fontaine (2002), whereby the summer monsoon rainfall over the Sahel would be sensitive to SM anomalies before the monsoon season over the Guinean Coast. When such anomalies are prescribed at the lower boundary conditions through the relaxation of ISBA towards the GSWP2 monthly climatology, the model does not show any improvement of the simulated summer monsoon rainfall. Note however that other regions do show a clear response to SM relaxation with an increase in both potential and effective predictability (Conil et al. 2006), suggesting that the low sensitivity obtained over West Africa is a regional rather than fundamental feature of the Arpege-Climat model. Finally, the stronger model sensitivity to SST rather than SM forcing suggests that the lagged statistical relationship between the Sahelian and previous second Guinean rainy seasons identified by Landsea et al. (1993) and Philippon and Fontaine (2002) could be an artefact. The possible influence of tropical SSTs on both rainy seasons is indeed an alternative hypothesis that will be now briefly discussed. But first, a comment is made about the apparent contradiction between our results and the multi-model West African "hot spot" found by Koster et al. (2004).

\subsection{The "hot spot" paradox}

In the recent GLACE (Global Land-Atmosphere Coupling Experiment) intercomparison project, Koster et al. (2004) made an attempt to evaluate the strength of the SM-precipitation coupling in twelve atmospheric GCMs and found that the Sahel was among the few regions where the coupling is relatively strong in most models. Though the study made an analogy with the precipitation sensitivity to SST anomalies in specific regions - "hot spots" - of the world ocean and their importance for seasonal climate 
prediction, the focus was not on interannual variability. The experiment design that was proposed to quantify the land-atmosphere coupling was based on boreal summer atmospheric integrations driven by observed year 1994 monthly mean SSTs in which subsurface SM was prescribed at each time step from a control experiment. The coupling strength was then evaluated as the relative impact of these specified versus interactive boundary conditions on the reproducibility of 6-day precipitation totals, i.e. the intraseasonal rather than interannual variability of precipitation. Of course, the magnitude of the high-frequency SM feedback has probably some connections with the potential influence of SM on interannual climate variability, but the study has serious limitations. First, it does not evaluate the coupling strength at the seasonal timescale which depends on the magnitude and persistence of the initial SM anomalies that are simulated at the beginning of the season. Secondly, it does not account for SST variability that is yet likely to dominate climate variability at the seasonal timescale.

The Arpege-Climat model did not participate in the GLACE intercomparison project, which again was not primarily designed to explore the atmospheric sensitivity to SM at the seasonal timescale. Nevertheless, it is here argued that ISBA does exhibit a significant SM-precipitation coupling over the Sahel and is not necessarily an outlier in this respect. This was clearly demonstrated by Douville et al. (2001) comparing ensembles of boreal summer atmospheric simulations in which SM was varied from wilting point to field capacity over sub-Saharan Africa and India respectively. The regional relaxation allowed us to isolate the local impact of SM, which was found to be significant over the Sahel and stronger than over India. Note also that the "real" strength of the land-atmosphere coupling over the Sahel remains unknown given the lack of ground truth and the considerable spread found in the GLACE sensitivity experiments.

Without running sensitivity experiments, it is possible to diagnose and compare the strength of the SM-precipitation feedback in control simulations with interactive SM based on a simple regional diagnostic such as the water vapor recycling rate proposed by Schär et al. (1999). The principle is to compute the line integral around the specified domain of the vertically integrated horizontal moisture transport normal to the domain boundaries, $\mathrm{IN}$, and then to define the recycling rate as the ratio $E /(E+I N)$ where $E$ is the surface evaporation estimated inside the domain. While such diagnostic calculations have inherent limitations and are scale-dependent, they were shown to provide a useful index of recycling (Bosilovich and Schubert 2002) and may be used as a tool for model intercomparison. Unfortunately, the calculations require moisture transport outputs that are not diagnosed in many GCMs and cannot be easily diagnosed a posteriori. Such a task could be a preliminary step to carry on the GLACE intercomparison initiative, even if the reproducibility of intraseasonal precipitation variability quantified by Koster et al. (2004) is only partly related to the recycling estimate of Schär et al. (1999). 
Here, we compare only the recycling ratio simulated by Arpege-Climat for different regions. Fig. 14 shows the mean annual cycle of the ratio estimated from FF and GG outputs over the three main areas highlighted as "hot spots" in GLACE. Not surprisingly, the African and Indian monsoon regions show a drop of the recycling rate at the beginning of the rainy season, associated with the dominant influence of moisture advection at this period. In keeping with Douville et al. (2001), the drop is more pronounced over India than over sub-Saharan Africa which shows a stronger SM-precipitation feedback during the monsoon season. Interestingly, the central great plains of North America show an opposite behaviour with maximum recycling during the early summer rainy season. But the main conclusion here is that the relaxation technique does not perturb the magnitude of the SM-precipitation feedback (FF and GG are very close) and that sub-Saharan Africa does not appear as an area with particularly low recycling rates compared to the other "hot spots" detected in GLACE (at least not lower than over India in boreal summer).

\subsection{How to reconcile model and obervations ?}

The easiest way to reconcile the significant observed relationship between the Sahelian and previous second Guinean rainy seasons and the low sensitivity of the Sahelian monsoon rainfall to SM in the Arpege-Climat model is to assume that the statistical link is an artefact that the model cannot reproduce. We can indeed imagine that both rainy seasons are partly controlled by common modes of SST variability that persist between the two seasons or by a sequence of such modes that links the two seasons. Ocean memory is indeed better documented than land memory and has been shown to extend from seasonal to multi-decadal timescales. The question is then to identify such modes of SST variability and to check that the influence of such modes on the West African monsoon is poorly captured by the atmospheric GCM.

For this purpose, we make use of a Maximum Covariability Analysis (MCA, Von Storch and Zwiers 1999), i.e. a statistical tool that can be considered as a generalization of the PCA. The objective is to identify pairs of singular vectors that explain a maximum of covariance between two space-timedependent variables. Each pair of singular vectors describes a fraction of the squared time covariance between the two fields and is associated with two timeseries of expansion coefficients (EC) that are equivalent to the PCs in the PCA. The correlation between the pair of ECs indicates the strength of the coupling between the singular vectors.

The MCA is here applied to JASO southern tropical Atlantic SSTs in year 0 and JJAS West African rainfall in year +1 . Fig. 15 shows the spatial patterns corresponding to the first mode of covariability. Since the variability of SST is here assumed to drive that of precipitation, we provide the SST 
homogeneous vector and the precipitation heterogeneous vector, i.e. the regression of grid-point SST and precipitation onto the timeseries of the first EC for the SST singular vector. This mode explains $66 \%$ of the covariability between the two fields (while the fraction of covariability explained by the second pair is less than 10\%). Fig. 15 indicates that positive (negative) SST anomalies in the Guinean Gulf are generally followed by a rainfall excess (deficit) over the Sahel in the following year, as indicated by the 0.55 correlation between the EC timeseries. Such a link is consistent with the lagged relationship between the Sahelian and previous second Guinean rainy seasons given the synchroneous correlations between the eastern equatorial Atlantic SSTs and the Guinean Coast precipitation (Fig. 4).

The next question is to understand what is the mechanism of ocean memory between the two rainy seasons? Fig. 16 shows lead-lag correlations of the first EC of southern tropical Atlantic SSTs with monthly anomalies of the SSR and GCR rainfall indices (in black). It confirms the biennial component of both indices and the resulting apparent link between Guinean rainfall in year 0 and Sahelian rainfall in year +1 . Also shown are the correlations with monthly SST indices over the Guinean Gulf and Niño-3 domains respectively (in grey). Year 0 excess in summer GCR is associated with warm anomalies in the Guinean Gulf, that also exhibit a quasi-biennial oscillation though not strong enough to explain that of precipitation. The key reason for the apparent remote (both in space and time) relationship between the two rainy seasons is the fact that the positive Guinean Gulf SST anomalies in year 0 are generally associated with a transition toward cold SSTs in the eastern equatorial Pacific that peak in summer of year +1 and then contribute to strengthen the Sahelian monsoon rainfall. Note that this result does not necessarily mean that Guinean Gulf SST is a precursor of ENSO (though such a statistical link is confirmed by a lagged MCA applied to Atlantic and Pacific SSTs over the whole 1911-1992 period). It only suggests that the out-of-phase interannual variations of the Atlantic and Pacific equatorial basins are partly responsible for the out-of-phase interannual variations of the Guinean and Sahelian summer rainfall and therefore of the first EOF of JJAS precipitation anomalies over West Africa (Fig. 3).

\section{Conclusion}

Despite a relatively abundant litterature on the subject, there are still many uncertainties regarding the contribution of SM to Sahelian monsoon rainfall predictability. There is also some confusion between local versus remote effects, and daily-to-weekly versus monthly-to-seasonal timescales. The aim of the present study was to clarify these issues by using both a statistical analysis of the instrumental record and an original set of numerical sensitivity experiments. While the filtering of the observed precipitation timeseries indicates that the lagged relationship between the Guinean (year 0 ) and Sahelian (year +1 ) rainy seasons is partly related to a multidecadal covariability, a significant correlation persists at the 
interannual timescale that is related to a quasi-biennial oscillation of the coupled Guinean Gulf - West African monsoon sytem and to the out of phase SST variability in the eastern equatorial Atlantic and Pacific and its influence on West African monsoon rainfall. Such a mechanism was not found in the Arpege-Climat model which can be explained by the limited ability of the model to capture the observed SST-monsoon teleconnection (Joly et al. 2006) and by the use of prescribed rather than interactive SSTS.

These results suggest that the apparent lagged relationship between the Guinean and Sahelian rainy seasons is mainly an artefact. This interpretation is reinforced by our numerical sensitivity experiments that do not support a SM regulation mechanism whereby the Sahelian monsoon rainfall would be influenced by the previous second Guinean rainy season. Whereas the use of a particular GCM is an obvious limitation of the present study, it is argued that the Arpege-Climat model produces dynamical seasonal prediction scores which are consistent with those of other european GCMs (DoblasReyes et al. 2005) and shows a significant positive SM-precipitation feedback over the Sahel in keeping with the multi-model "hot spot" identified in the GLACE intercomparison project. Yet, the low sensitivity of West African monsoon predictability to SM found in our simulations could be a specific response and similar experiments should be performed with other GCMs, in particular with those that are more successful at simulating the SST-monsoon teleconnections (Joly et al. 2006). While the evaporation anomalies simulated by the ISBA land surface model are consistent with the multi-model GSWP2 analysis, other physical processes such as vertical diffusion and convection can also exert a significant impact on the land-atmosphere coupling and are obviously model dependent. Another uncertainty is related to the prescribed SST forcing that may lead to an overestimation of the SST influence and, by extension, to an underestimation of the SM impact. In addition, the use of a climatological annual cycle of vegetation is another limitation and more sophisticated land surface models with interactive vegetation could also be tested. Nevertheless, while such interaction is probably relevant at the multidecadal timescale, its influence on interannual variability has still to be demonstrated.

Finally, the diagnostic recycling rate derived from the Arpege-Climat model outputs suggests that the SM-precipitation feedback does not only vary in space, but also in time. Over the Sahel, it shows a significant increase from July to September, which is consistent with the picture of a sudden moisture advection that gradually weakens when the land-sea thermal contrast vanishes in the course of the monsoon season. This feature can explain why the impact of the SM relaxation on seasonal rainfall predictability is stronger at the end than at the beginning of the rainy season. When it comes to predicting the precipitation accumulation over the whole monsoon season, SM probably plays a secondary role compared to SST variability. Improving our understanding and the simulation of the West 
African monsoon teleconnections with tropical SSTs remains a priority to improve seasonal forecasting over the Sahel.

Acknowledgements: This work has been supported by the European Commission Sixth Framework Program (ENSEMBLES contract GOCE-CT-2003-505539) and by the AMMA (African Monsoon Multidisciplinary Analysis) project. Based on a French initiative, AMMA was built by an international scientific group and is currently funded by a large number of agencies, especially from France, UK, US and Africa. It has also been the beneficiary of a major financial contribution from the European Commission Sixth Framework Program. Detailed information on scientific coordination and funding is available at http://www.amma-international.org. The EOF and MCA analyses have been performed using the Statpack statistics software developed by Pascal Terray and most figures have been prepared using the GrADS graphics software. Thanks are also due to Nathalie Philippon and Aaron Boone, as well as to Huqiang Zhang and an anonymous reviewer, for their comments on the original manuscript. 


\section{References}

Bosilovich MG, Schubert SD (2002) Water vapor tracers as diagnostics of the regional hydrological cycle. J Hydrometeorol 3:149-165

Charney JG, Quirk WJ, Chow S, Kornfield J (1977) A comparative study of the effects of albedo change on droughts in semi-arid regions. J Atmos Sci, 34:1366-1385

Conil S, Douville H, Tyteca S (2006) The relative roles of soil moisture and SST in climate variability explored within ensembles of AMIP-type simulations. Climate Dyn doi:10.1007/s00382-006-0172-2

Conil S, Douville H (2006) Impact of initial versus boundary conditions of soil moisture on atmospheric predictability at the seasonal timescale. Climate Dyn (in preparation)

Decharme B, Douville H (2006) Global validation of the ISBA sub-grid hydrology. Climate Dyn (revised)

Déqué M, Dreveton C, Braun A, Cariolle D (1994) The ARPEGE/IFS atmosphere model, A contribution to the French Community climate modelling. Climate Dyn 10:249-266

Dirmeyer $\mathrm{P}(2005)$ The land surface contribution to the potential predictability of boreal summer season climate. J Hydrometeo 6:618-632

Dirmeyer P, X Gao, M Zhao, Z Guo, T Oki, N Hanasaki (2005) The second Global Soil Wetness Project (GSWP-2): Multi-model analysis and implications for our perception of the land surface. COLA Technical Report \#185, 46 pp

Doblas-Reyes F, Hagedorn R, Palmer TN (2005) The rationale behind the success of multi-model ensembles in seasonal forecasting. Part II: Calibration and combination. Tellus A 57:234-252

Douville $H$ (1998) Validation and sensitivity of the global hydrological budget in stand-alone simulations with the ISBA land surface scheme. Climate Dyn 14:151-171

Douville H, Viterbo P, Mahfouf J-F, Beljaars ACM (2000) Validation of the optimum interpolation technique for sequential soil moisture analysis using FIFE data. Monthly Weather Rev 128:1733-1756 
Douville H, Chauvin F (2000) Relevance of soil moisture for seasonal climate predictions: a preliminary study. Climate Dyn 16:719-736

Douville $H$, Chauvin F, Broqua $H$ (2001) Influence of soil moisture on the Asian and African monsoons. Part I: Mean monsoon and daily precipitation. J. Climate 15:701-720

Douville H (2002) Influence of soil moisture on the Asian and African monsoons. Part II: Interannual variability. J. Climate 15:701-720

Douville H (2003) Assessing the influence of soil moisture on seasonal climate variability with AGCMs J. Hydrometeo 4:1044-1066

Douville H (2004) Relevance of soil moisture for seasonal atmospheric predictions: Is it an initial value problem? Climate Dyn 22:429-446

Ferranti L, Viterbo P (2006) The European summer of 2003 : sensitivity to soil water initial conditions. J Climate 19:3659-3680

Folland CK, Palmer TN, Parker DE (1986) Sahel rainfall and wordwide sea temparatures, 1901-85. Nature 320:602-607

Folland CK, Owen JA, Ward MN, Colman AW (1991) Prediction of seasonal rainfall in the Sahel region using empirical and dynamical methods. J Forecasting 10:21-56

Fontaine B, Philippon N (2000) Seasonal evolution of boundary layer heat content in the West African monsoon from the NCEP/NCAR reanalysis (1968-1998). Int J Climatol 20:1777-1790

Garric G, H Douville, M Déqué (2002) Prospects for improved seasonal forecasts of monsoon precipitation over Sahel. Int J Climatol 22:331-345

Giannini A, Saravan R, Chang P (2003) Oceanic forcing of Sahel rainfall on interannual to interdecadal time scales. Science 302:1027-1030 
Guérémy J-F, Déqué $M$, Braun A, Piedelievre J-P (2005) Actual and potential skill of seasonal predictions using the CNRM contribution to DEMETER: coupled versus uncoupled model Tellus $A$ 57:308-319

Hulme M, TJ Osborn, TC Johns (1998) Precipitation sensitivity to global warming: comparison of observations with HadCM2 simulations. Geophys Res Lett 25:3379-3382

Janicot S, Trzaska S, Poccard I (2001) Summer Sahel-ENSO teleconnection and decadal time scale SST variation. Climate Dyn 18:303-320

Joly M, Voldoire A, Douville H, Terray P, Royer J-F (2006) African monsoon teleconnections with tropical SSTs in a set of IPCC4 coupled models. Climate Dyn (in press)

Koster R, Suarez M, Heiser M (2000) Variability and predictability of precipitation at seasonal to interannual timescales. J Hydrometeo 1:26-46

Koster R, and the Glace Team (2004) Regions of strong coupling between soil moisture and precipitation. Science 305:1138-1140

Lamb PJ (1978) Large-scale tropical Atlantic surface circulation patterns associated with sub-Saharan weather anomalies. Tellus 30:240-251

Landsea CW, Gray WM, Mielke MW, Berry KJ (1993) Predictability of seasonal Sahelian rainfall by 1 December of the previous year and 1 June of the current year. In Preprints of the $20^{\text {th }}$ Conference on Hurricanes and Tropical Meteorology, AMS, San Antonio, 473-476

Manabe S, Delworth T (1990) The temporal variability of soil wetness and its impact on climate. Climatic Change 16:185-192

Mitchell TD, PD Jones (2005) An improved method of constructing a database of monthly climate observations and associated high-resolution grids. Int J Climatol 25:693-712 
Palmer TN, Alessandri A, Andersen U, Cantelaube P, Davey M et al. (2004) Development of a European multi-model ensemble system for seasonal to interannuel prediction (DEMETER). Bull Am Met Soc 85:863-872

Philippon N, Fontaine B (2002) The relationship between the Sahelian and previous $2^{\text {nd }}$ Guinean rainy seasons: a monsoon regulation by soil wetness? Annales Geophysicae 20:575-582

Rayner NA, Parker DE, Horton EB, Folland CK, Alexander LV, Rowell DP, Kent EC, Kaplan A (2003) Global analyses of sea surface temperature, sea ice and night maritime air temperature since the late nineteenth century. J Geophys Res $108: 4407-4415$ doi:10.1029/2002JD002670

Rowell D-P (1998) Assessing potential seasonal predictability with an ensemble of multidecadal GCM simulations. J Climate 11:109-120

Beck C, J Grieser, B Rudolf (2005) A new monthly precipitation climatology for the global land areas for the period 1951 to 2000. DWD, Klimastatusbericht 2004.

Schär C, Lüthi D, Beyerle U (1999) The soil-precipitation feedback: a process study with a regional climate model. J Climate 12:722-741

Shinoda M, Yamaguchi Y (2003) Influence of soil moisture anomaly on temperature in the Sahel: A comparison between wet and dry decades. J Hydrometeorol 4:437-447

Shukla J (1998) Predictability in the midst of chaos: a scientific basis for climate forecasting. Science 282:728-731

Trenberth K-E, Branstator G-W, Karoly D, Kumar A, Lau N-C, Ropelewski C (1998) Progress during TOGA in understanding and modelling global teleconnections associated with tropical sea surface temperatures. J Geophys Res 103:14291-14324

Von Storch H, Zwiers F (1999) Statistical Analysis in Climate Research. Cambridge University Press.

Wang G, Eltahir EAB, Foley JA, Pollard D, Levis S (2004) Decadal variability of rainfall in the Sahel: results from the coupled GENESIS-IBIS atmosphere-biosphere model. Climate Dyn 22:625-637 
Ward MN (1998) Diagnosis and short-lead time prediction of summer rainfall in tropical North Africa at interannual and multidecadal timescales. J Climate 11:3167-3191

Wu W, Dickinson R (2004) Time scales of layered soil moisture memory in the context of landatmosphere interaction. J Climate 17:2752-2764 
List of Tables

\begin{tabular}{ccc}
\hline Name of expt & SST & SM \\
\hline EE & Climatological & Relaxed toward GSWP2 \\
FF & Observed & Fully interactive \\
GG & Observed & Relaxed toward GSWP2 \\
\hline
\end{tabular}

Table 1: Summary of the experiments 


\section{List of Figures}

Figure 1: CRU2 annual anomalies of Sudan-Sahel (in red) and Guinean Coast (in green) rainfall indices (see text for the definition) relative to the 1971-2000 climotology. Thick lines represent low-pass filtered anomalies using a digital filter with a 10-year frequency cutoff.

Figure 2: Monthly anomalies of SM (upper panels) and surface evaporation (lower panels) relative to the 1986-1995 climatology over sub-Saharan Africa (left panels) and the Guinean Coast (right panels). Three climatologies are compared: the ISBA analysis (solid line), the multi-model GSWP2 analysis (dotted line) and the ERA40 reanalysis (dashed line).

Figure 3: Leading spatial patterns (EOFs) of filtered JJAS precipitation anomalies over West Africa based on the CRU2 climatology over the 1911-1992 period. VF is the fraction of variance explained by each EOF.

Figure 4: Global correlation maps between the leading PCs of JJAS West African rainfall and JJAS gridcell SST anomalies (detrended and filtered) from the HadSST.1 climatology. The correlations are estimated over the 1911-1992 period. VF is the fraction of variance explained by each EOF.

Figure 5: a) Lead-lag correlations of the leading PCs of JJAS West African rainfall in year 0 with monthly anomalies in SSR (as well as GCR for the first PC) from year -1 to year +1 . Note that the monthly timeseries have been filtered with a 5-month moving average to smooth the correlations that have been estimated over the 1911-1992 period. b) 31-year sliding correlations between the first 4 PCs of JJAS West African rainfall and JJAS anomalies in SSR (as well as GCR for the first PC). Correlations with SSR are in solid lines and correlations with GCR are in dashed lines. In both a) and b), the 5\% significance levels are indicated by dashed horizontal lines.

Figure 6: Regional correlation maps between JJAS SSR in year 0 and SON (a,b,c) or JASO (d) grid-cell precipitation anomalies in year -1: a) Raw anomalies, b) detrended anomalies, $c, d)$ high-pass filtered anomalies. The correlations are estimated over 1901-2000 in a and b, and over 1911-1992 in c and d due to the filtering of the timeseries.

Figure 7: a) Lead-lag correlations between JJAS SSR in year 0 and monthly GCR anomalies from year -1 to year +1 (also shown are the auto-correlations with the filtered SSR timeseries). Note that the 
monthly timeseries have been filtered with a 5-month moving average to smooth the correlations that have been estimated over the 1911-1992 and 1901-2000 periods for filtered and unfiltered anomalies respectively. b) 31-year sliding correlations between JJAS SSR in year 0 and JASO GCR in year -1 . In both a) and b), the $5 \%$ significance levels are indicated by dashed horizontal lines.

Figure 8: Mean annual cycle of SM (a,b), surface evaporation $(c, d)$ and precipitation (e,f) over Sudan and Sahel $(a, c, e)$ and the Guinean Coast (b,c,f). Experiments FF and GG are compared with the ERA40 reanalysis (1958-2001) or with the CRU2 climatology (1951-2000). Also shown is the GSWP2 analysis (1986-1995) that has been used to derive our SM climatology (and the associated evaporation climatology and precipitation forcing).

Figure 9: Annual cycle of zonal mean $\left(20^{\circ} \mathrm{W}-25^{\circ} \mathrm{E}\right)$ total variability (left panels in $\mathrm{mm} /$ day) and potential predictability (right panels in \%) of surface evaporation over West Africa (land grid points only) between $10^{\circ} \mathrm{S}$ and $40^{\circ} \mathrm{N}$.

Figure 10: Same as Fig. 9, but for precipitation.

Figure 11: Regional maps of temporal Anomaly Correlation Coefficients (ACC) between simulated and analysed (GSWP2) or observed (CRU2) JJAS anomalies over the 1986-1995 period for surface evaporation (left panels) and precipitation (right panels) respectively.

Figure 12: 10-year evolution of simulated (black squares) versus observed (red circles) anomalies of surface evaporation ( $\mathrm{mm} /$ day) over Sudan and Sahel. Anomalies are averaged from July to September $(a, b, c)$ or from August to November $(d, e, f)$. Results are shown for FF $(a, d), G G(b, e)$ and $E E(c, f)$ respectively. Besides the ensemble mean anomalies simulated in each experiment, the minimum and maximum values (thin lines) and the mean plus or minus one standard deviation (triangles) estimated from the 10 members are also shown to illustrate the model spread.

Figure 13: Same as in Fig. 12, but for precipitation (SSR).

Figure 14: Annual cycle of regional water vapour recycling ratio (see the text for details) in the FF and GG experiments over three regions, including sub-Saharan Africa (top panel) highlighted as "hot spots" in the GLACE intercomparison project. 
Figure 15: First mode of a Maximum Covariability Analysis applied to JASO southern tropical Atlantic SSTs in year 0 and JJAS West African rainfall in year +1 (filtered data over the 1911-1992 period). Left: JJAS rainfall heterogeneous vector (mm/day). Right: JASO SST homogeneous vector (K). This first pair of vectors explains $66 \%$ of the covariability between the two fields. VF is the fraction of variance explained by each mode and $R$ is the correlation between each pair of ECs. Note that the grid cells where the local regression onto the SST EC1 timeseries is not significant have been masked on both maps.

Figure 16: Lead-lag correlations of the first EC of JASO southern tropical Atlantic SSTs from the MCA shown in Fig. 15 with monthly anomalies in SSR and GCR (in black), as well as with monthly SST anomalies (in grey) over the Guinean Gulf $\left(5^{\circ} \mathrm{S}-5^{\circ} \mathrm{N} / 30^{\circ} \mathrm{W}-10^{\circ} \mathrm{E}\right)$ and the Niño-3 domain $\left(5^{\circ} \mathrm{S}\right.$ $\left.5^{\circ} \mathrm{N} / 30^{\circ} \mathrm{W}-10^{\circ} \mathrm{E}\right)$. Note that the monthly timeseries have been filtered with a 5-month moving average to smooth the correlations that have been estimated over the 1911-1992 period. The 5\% significance level of correlations is indicated by dashed horizontal lines. 


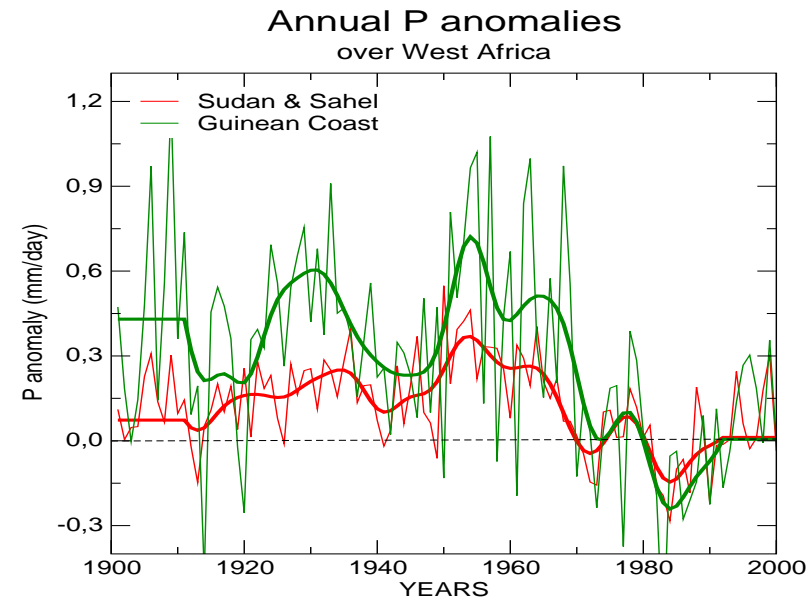

Figure 1: 
Monthly soil moisture anomalies (mm)

Sudan-Sahel $\left[10^{\circ} \mathrm{N}-20^{\circ} \mathrm{N} / 20^{\circ} \mathrm{W}-40^{\circ} \mathrm{E}\right]$

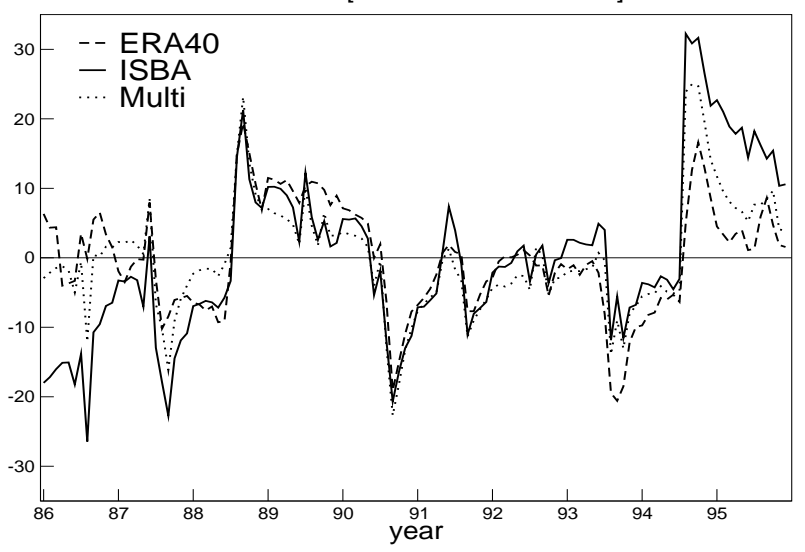

Monthly evaporation anomalies $(\mathrm{mm} / \mathrm{d}$ ) Sudan-Sahel $\left[10^{\circ} \mathrm{N}-20^{\circ} \mathrm{N} / 20^{\circ} \mathrm{W}-40^{\circ} \mathrm{E}\right]$

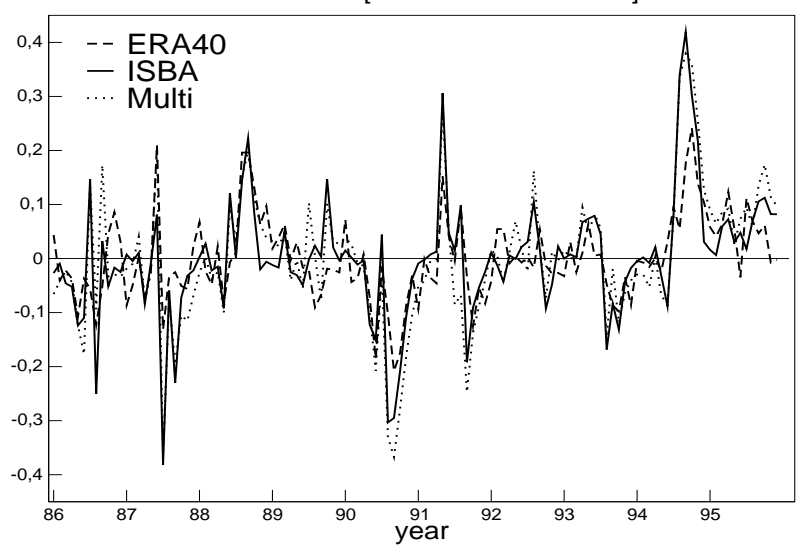

Monthly soil moisture anomalies (mm) Guinean Coast $\left[4^{\circ} \mathrm{N}-10^{\circ} \mathrm{N} / 15^{\circ} \mathrm{W}-10^{\circ} \mathrm{E}\right]$

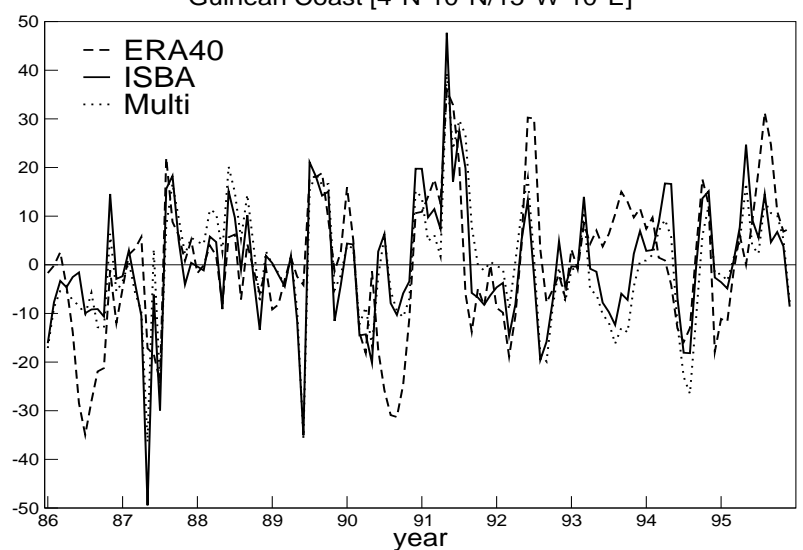

Monthly evaporation anomalies ( $\mathrm{mm} / \mathrm{d}$ )

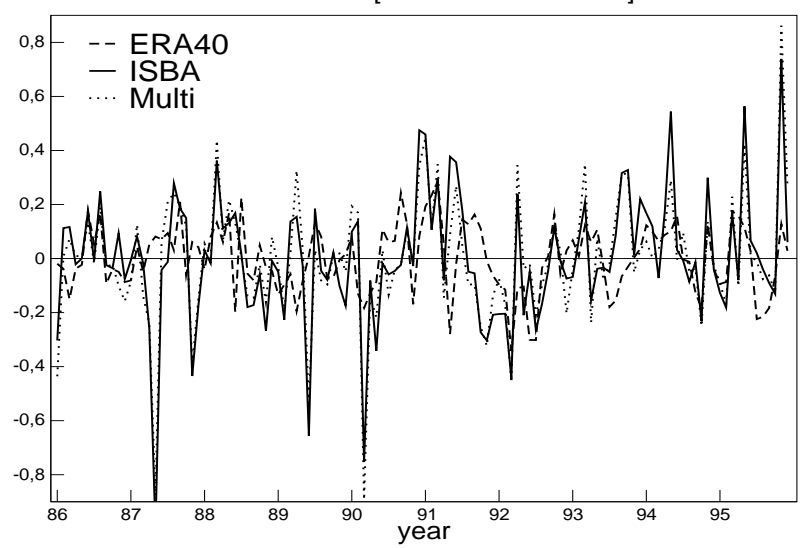

Figure 2: 
EOF of CRU2 JJAS $P$
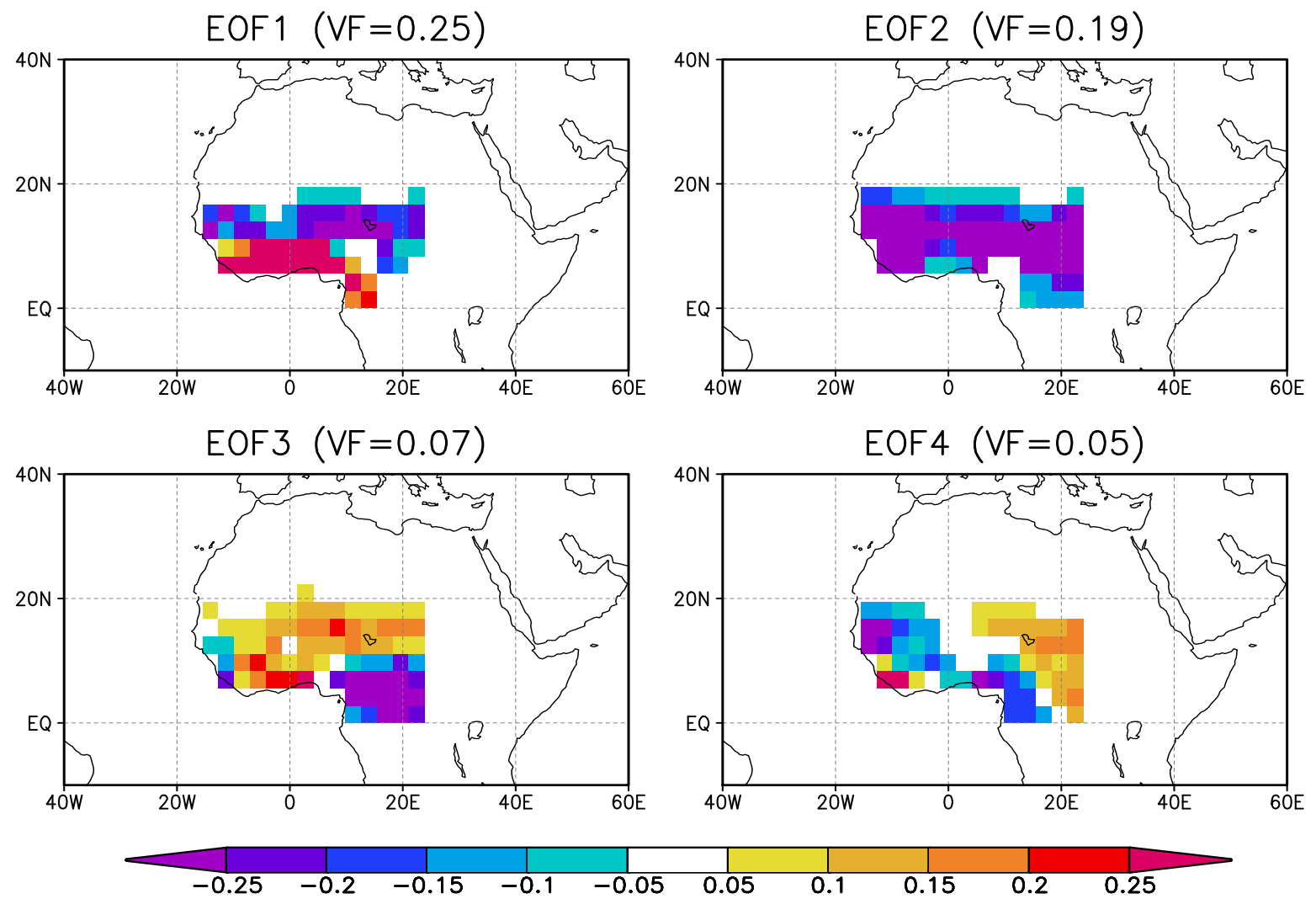

Figure 3: 

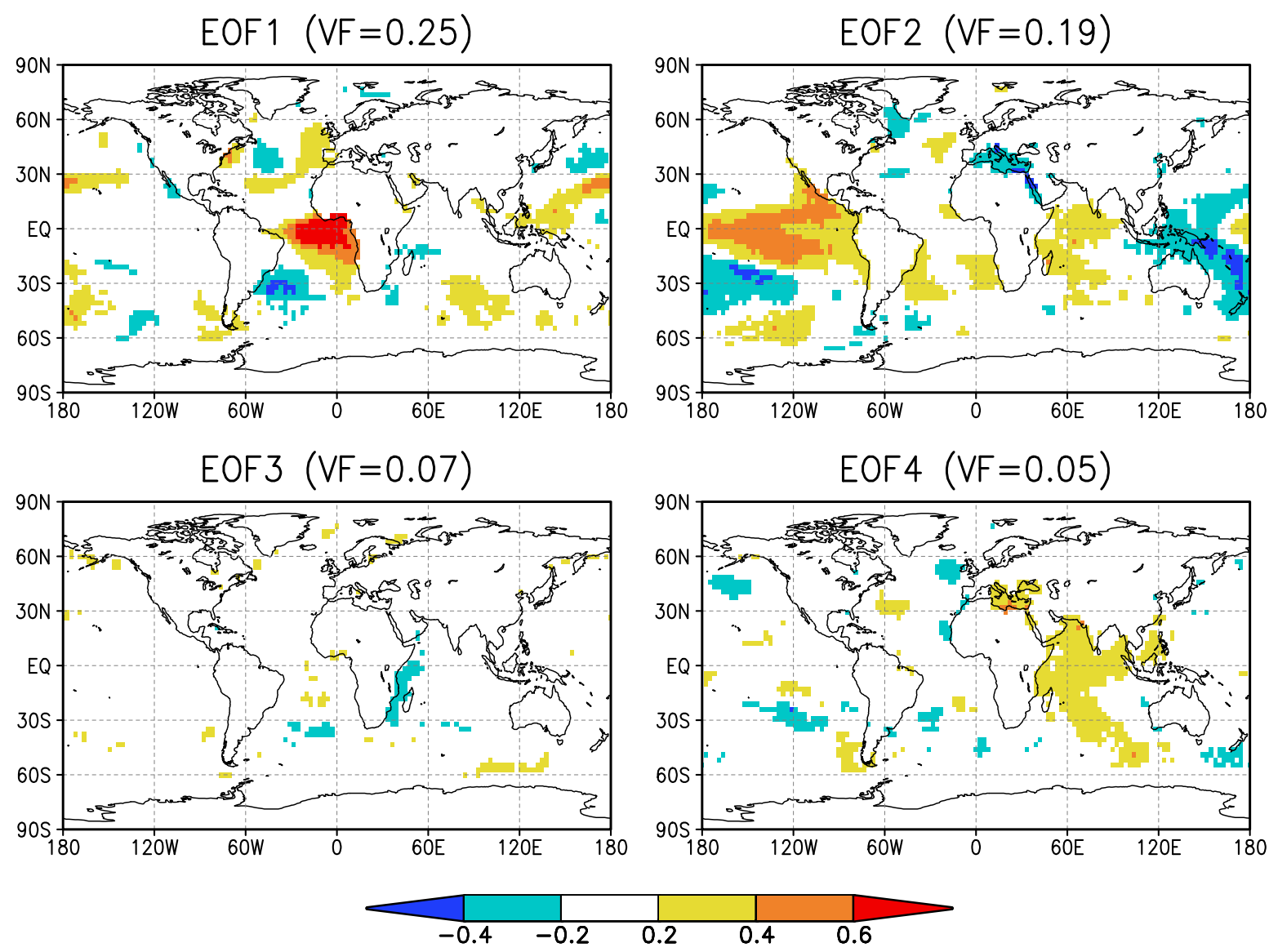

Figure 4: 
a) Lead/lag monthly correlations between SSR and PCs of JJAS West African P

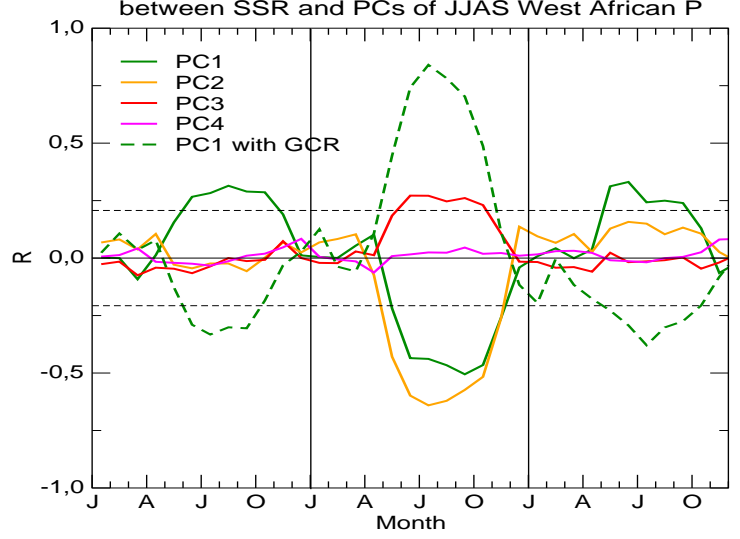

b) Sliding correlations

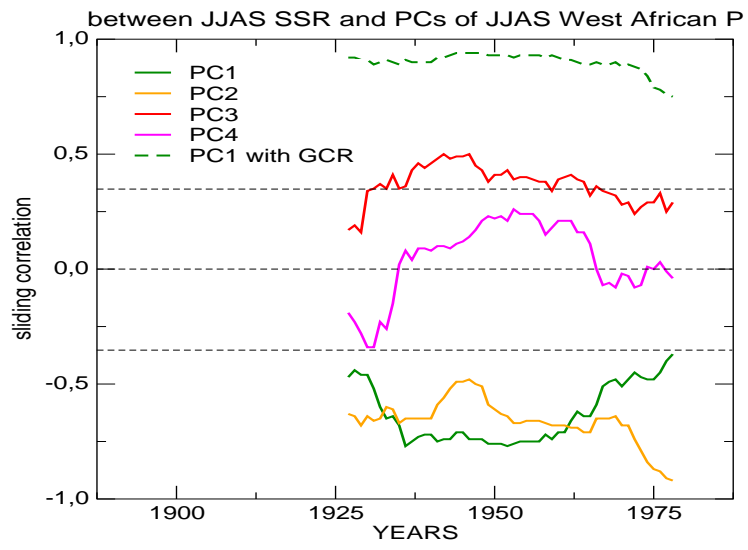

Figure 5: 
a) SON-1 raw anomalies

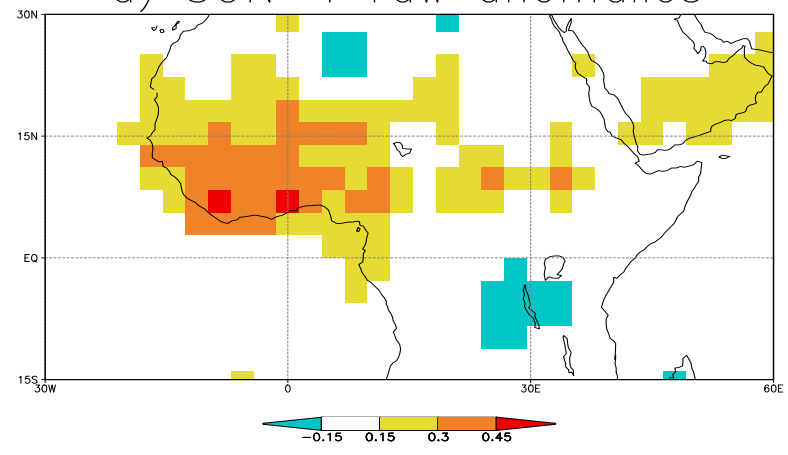

c) SON-1 filtered anomalies

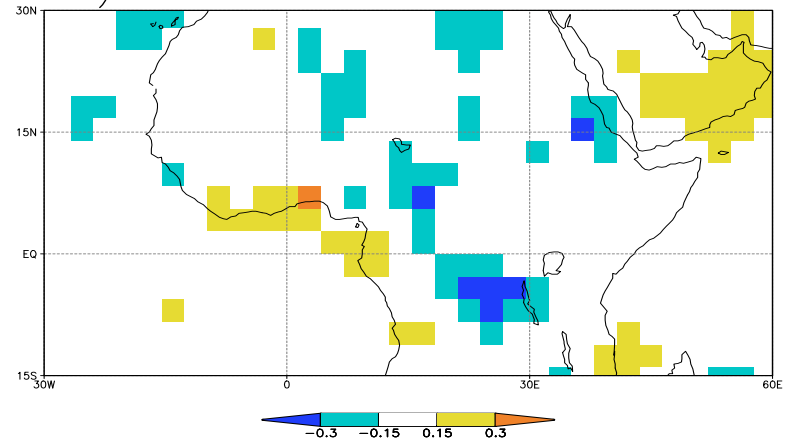

b) SON-1 detrended anomalies

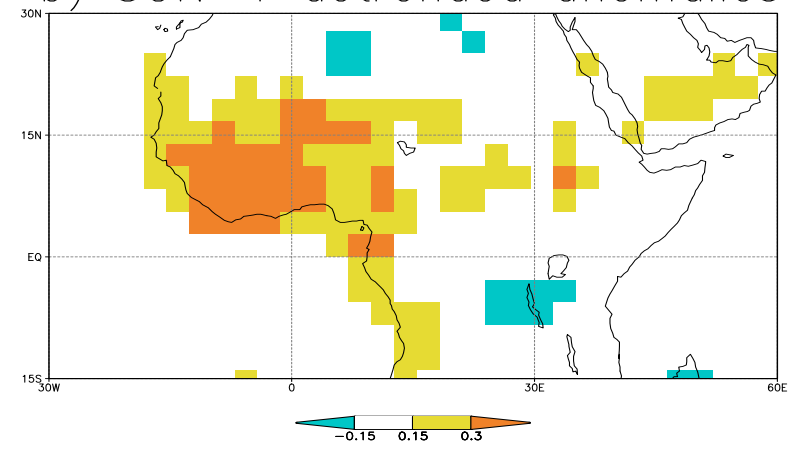

d) JASO-1 filtered anomalies

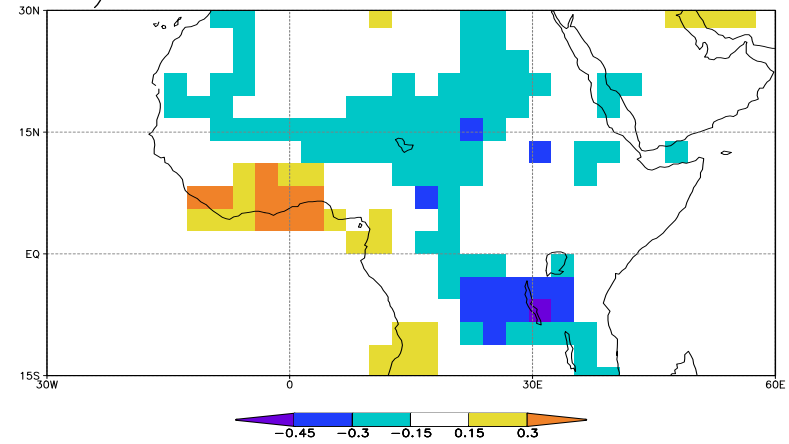

Figure 6: 
a) Lead/lag monthly correlations

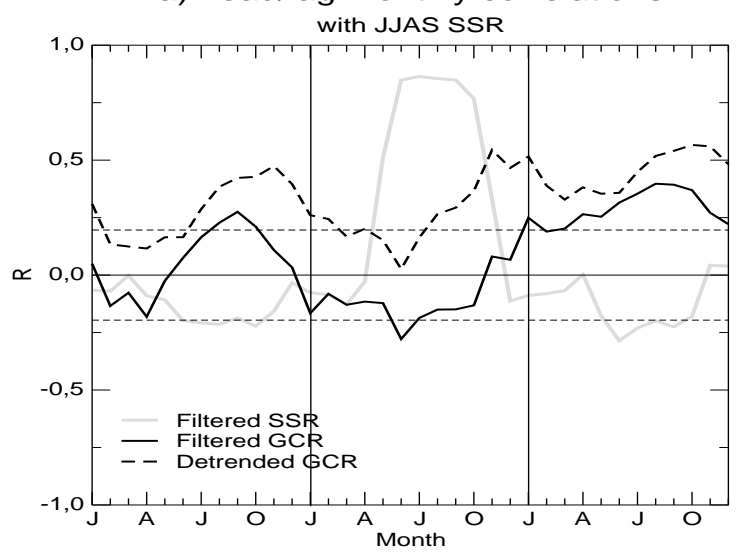

b) Sliding correlations

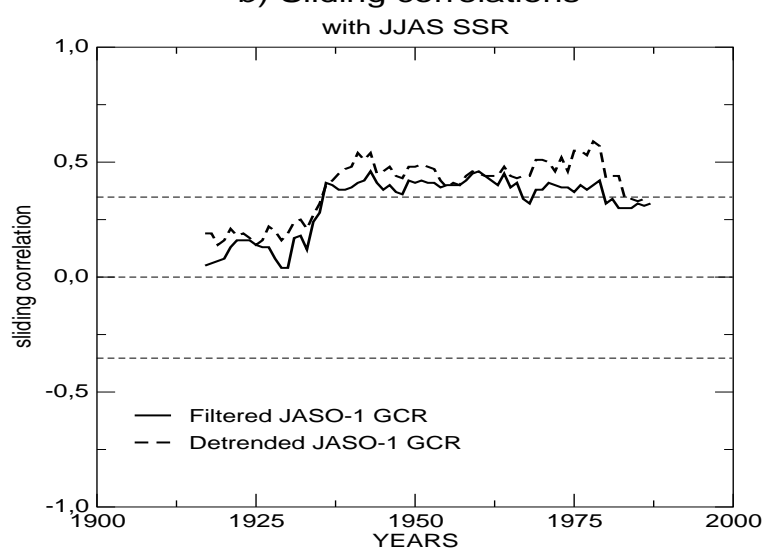

Figure 7: 
a) Annual cycle of $S M$

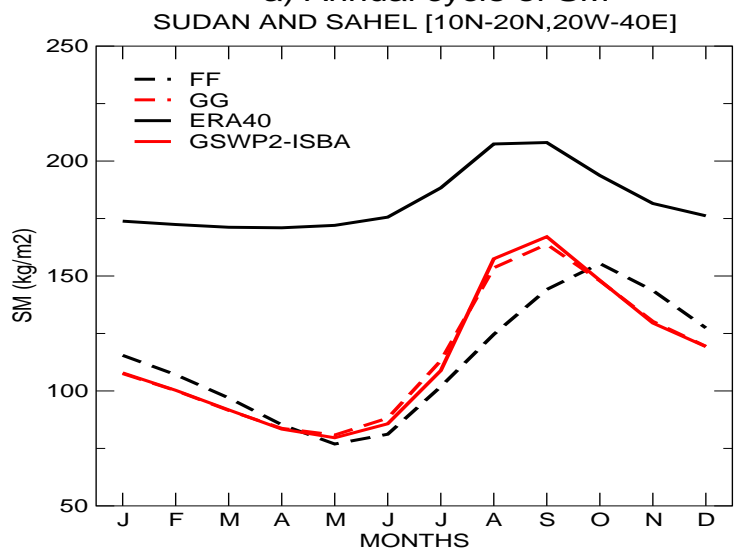

c) Annual cycle of $\mathrm{E}$

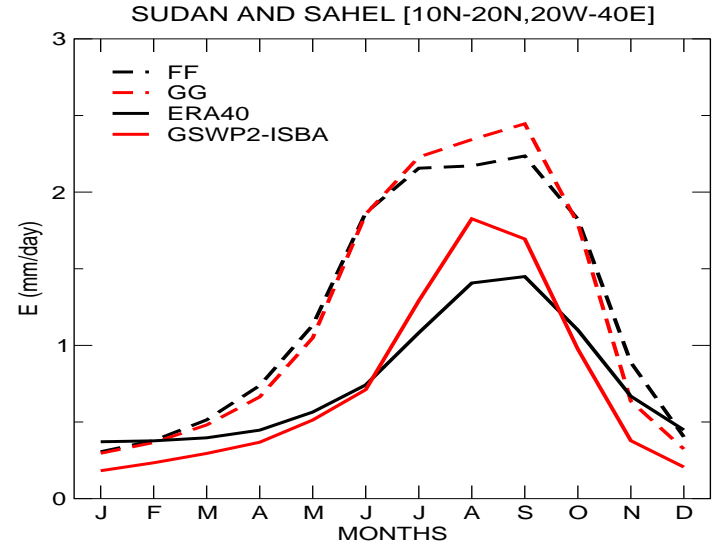

e) Annual cycle of SSR SUDAN AND SAHEL [10N-20N,20W-40E]

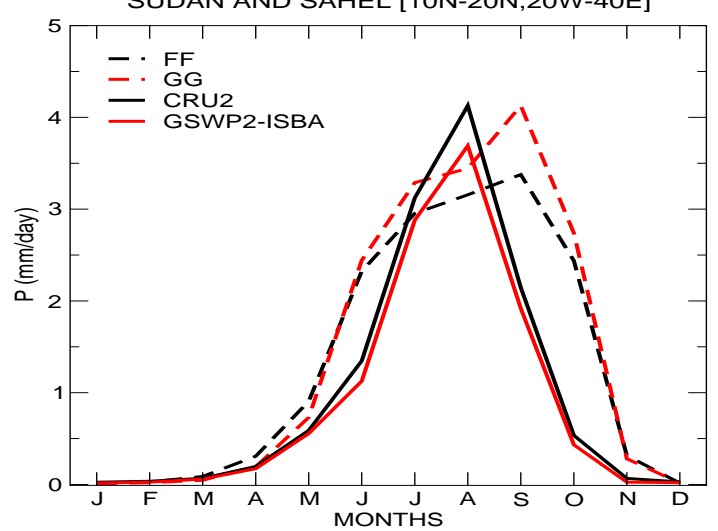

b) Annual cycle of SM GUINEAN COAST [4N-10N,15W-10E]

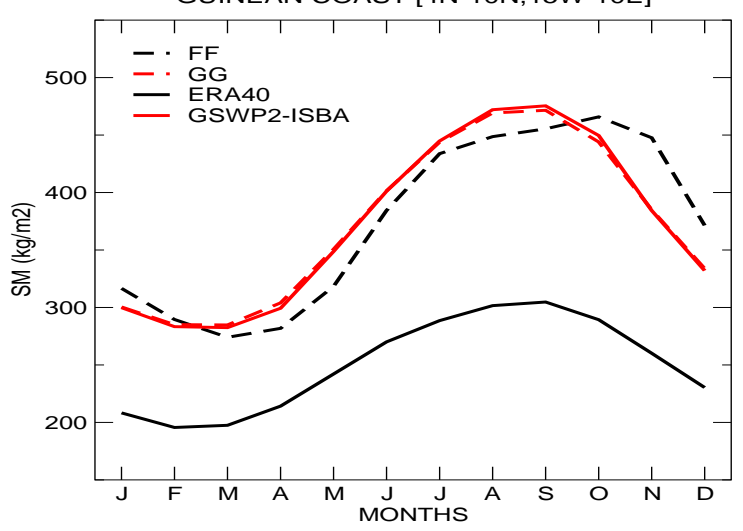

d) Annual cycle of $E$ GUINEAN COAST [4N-10N,15W-10E]

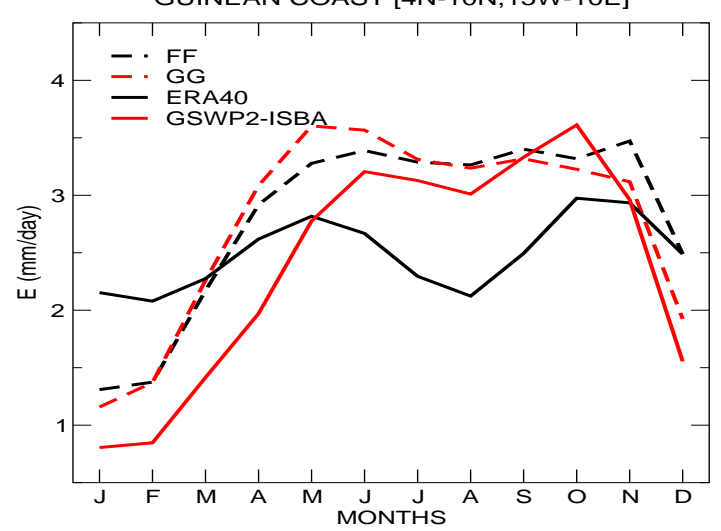

f) Annual cycle of GCR

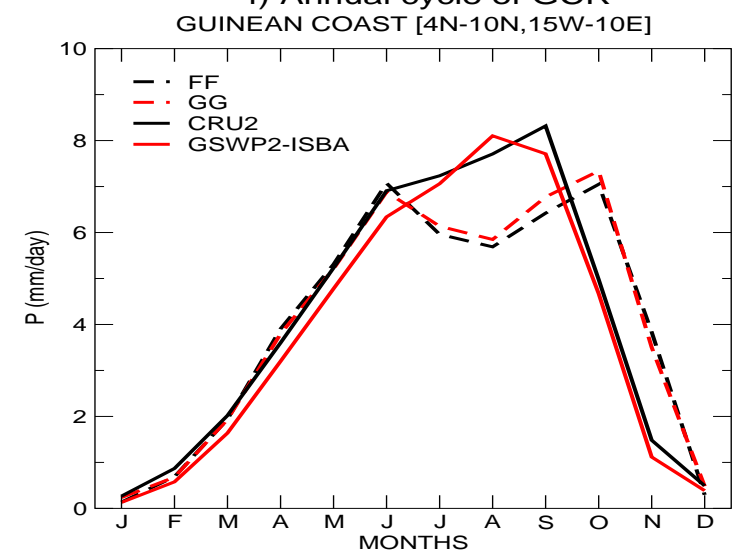

Figure 8: 
a) Total variability EVAP FF

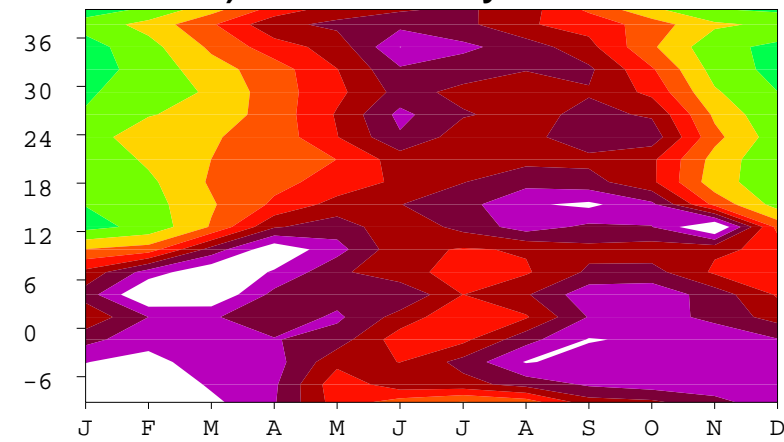

C) Total variability EVAP GG

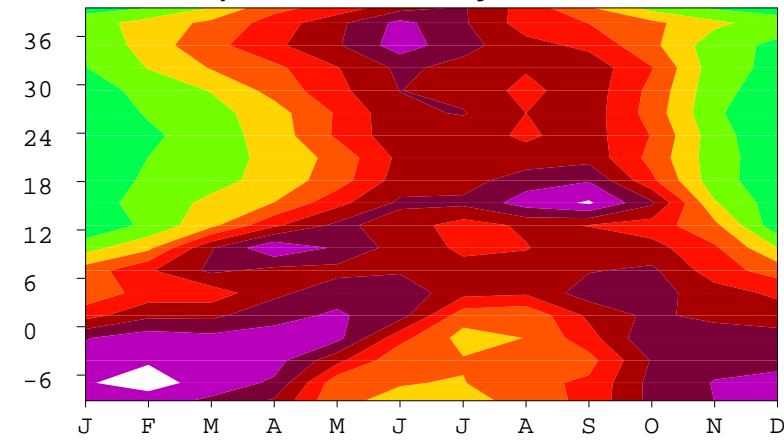

e) Total variability EVAP EE

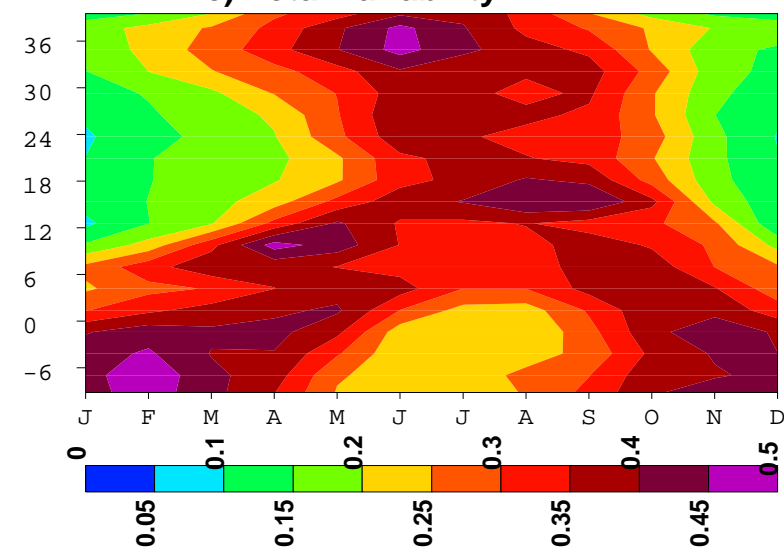

b) Pot Pred EVAP FF

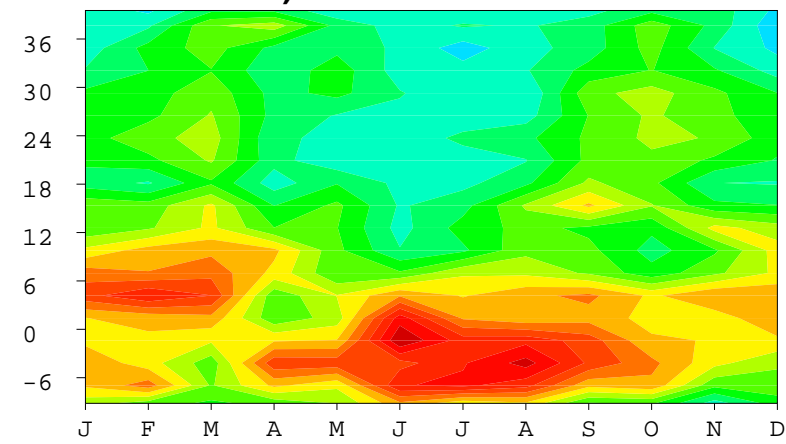

d) Pot Pred EVAP GG

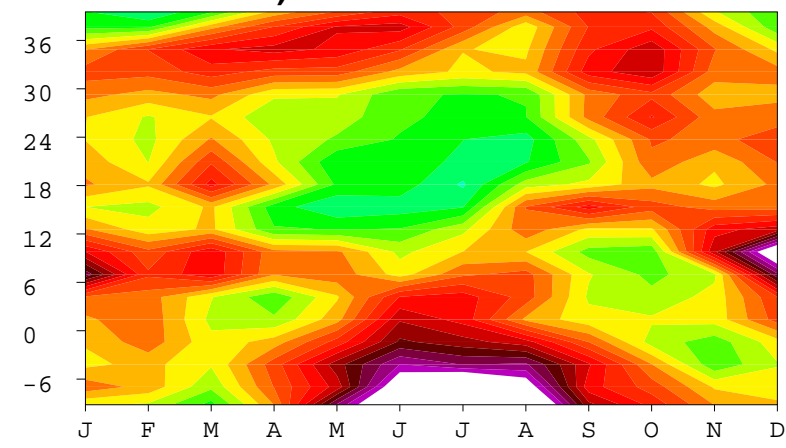

f) Pot Pred EVAP EE

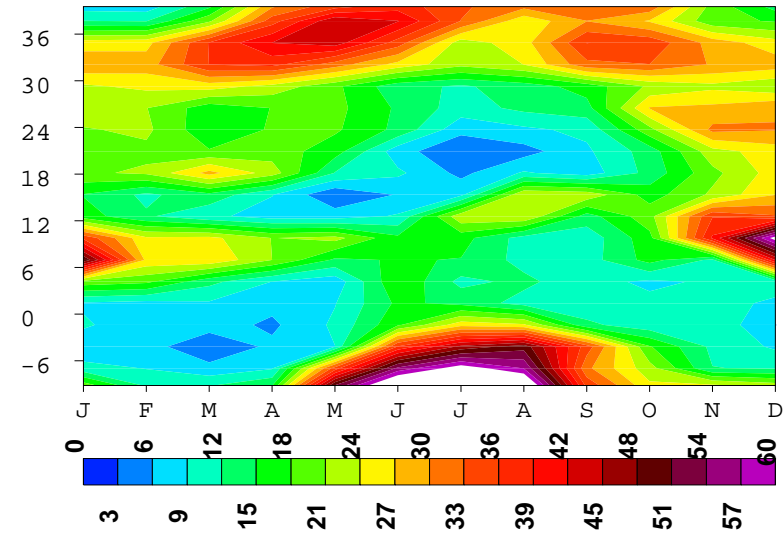

Figure 9: 
a) Total variability PTOT FF

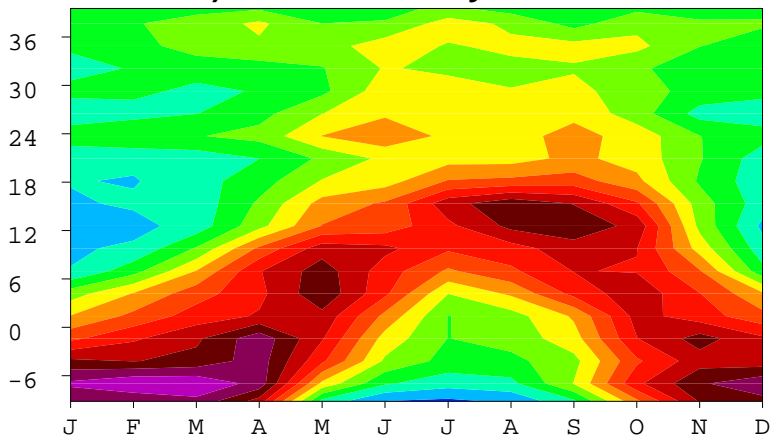

c) Total variability PTOT GG

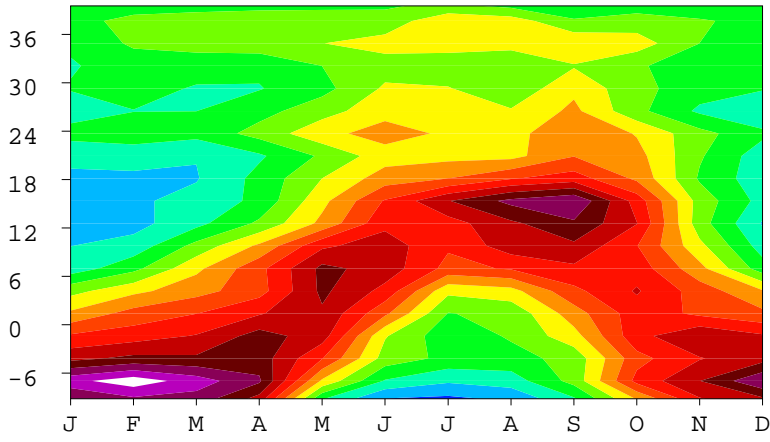

e) Total variability PTOT EE

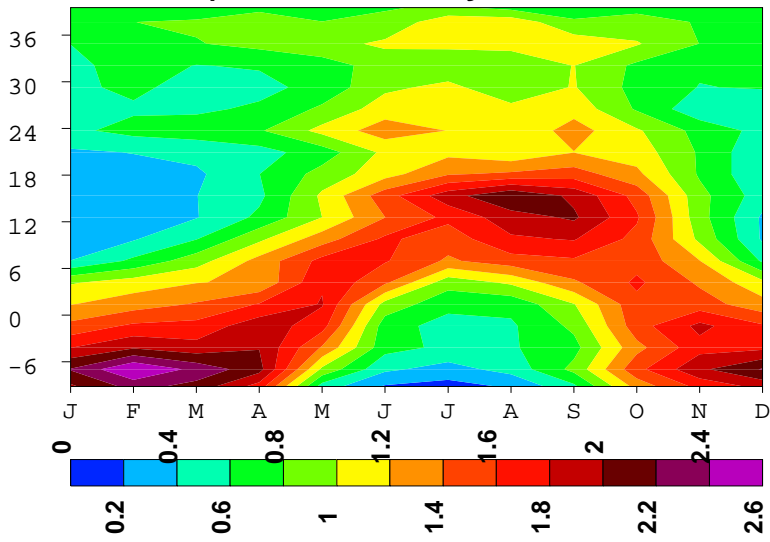

b) Pot Pred PTOT FF

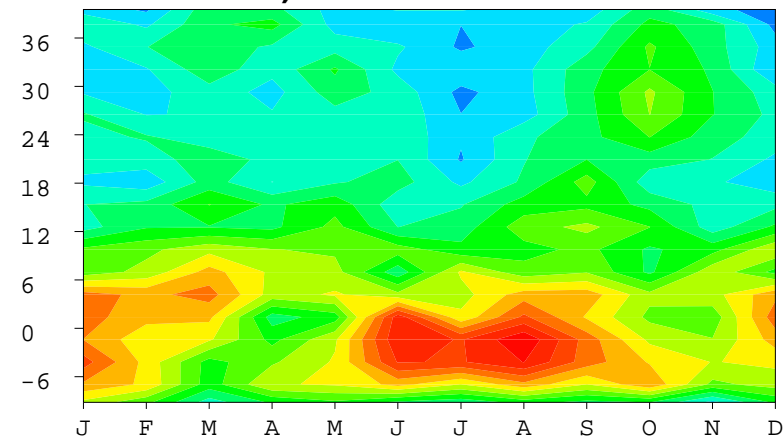

d) Pot Pred PTOT GG

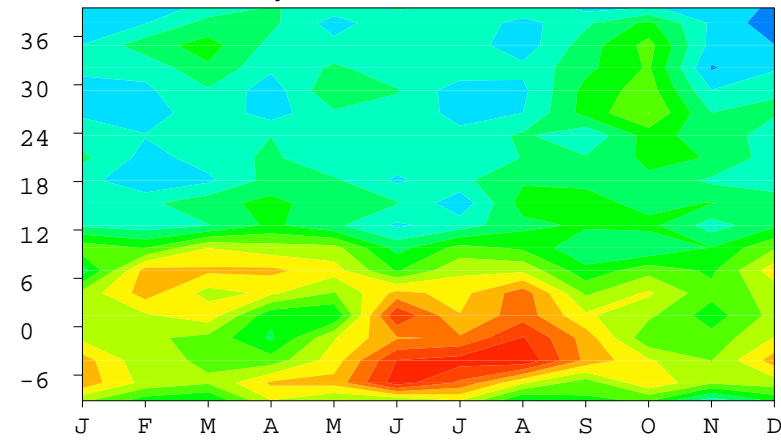

f) Pot Pred PTOT EE

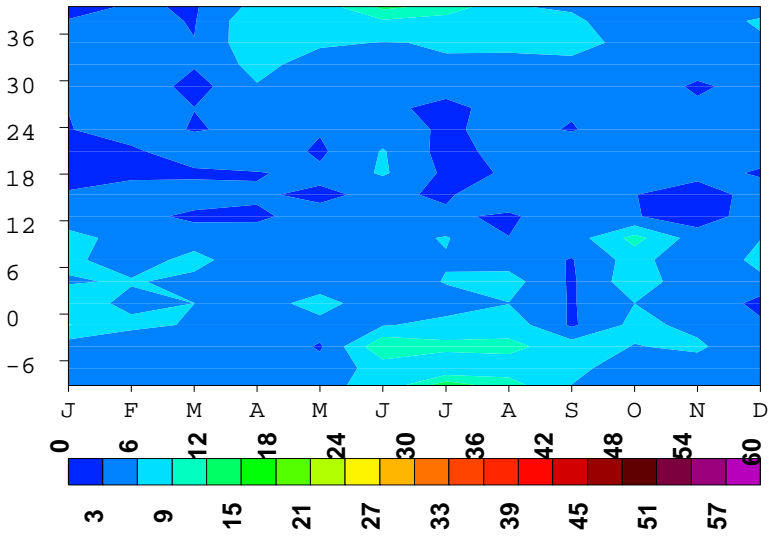

Figure 10: 
ACC EVAP JJAS FF/obs 1986-95

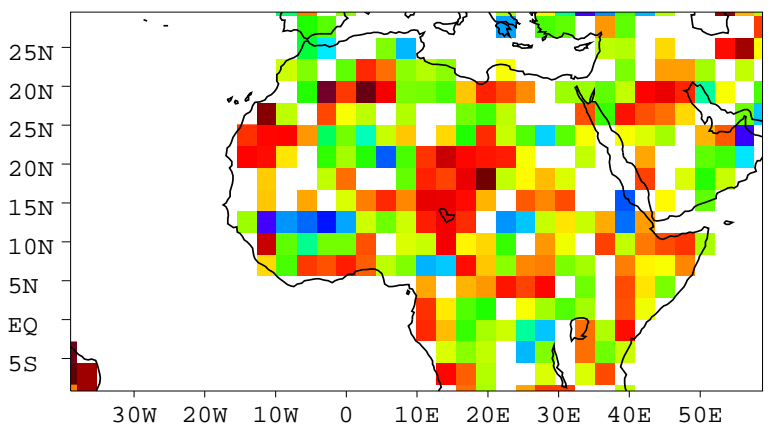

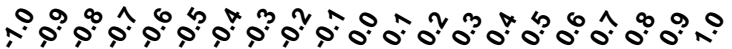

ACC EVAP JJAS GG/obs 1986-95

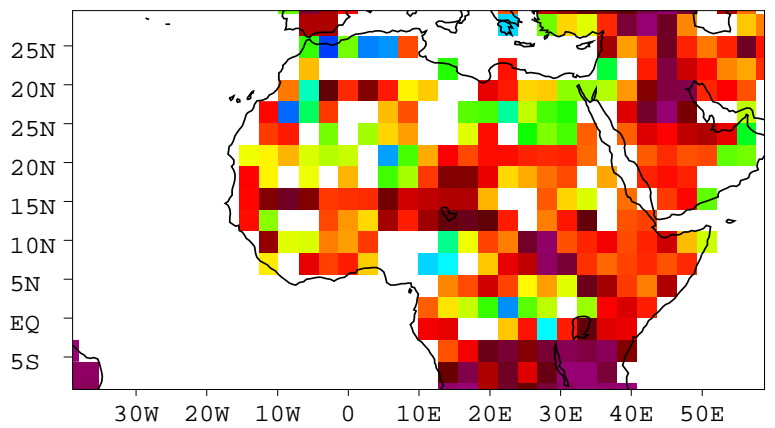

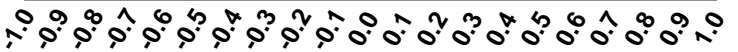

ACC EVAP JJAS EE/obs 1986-95

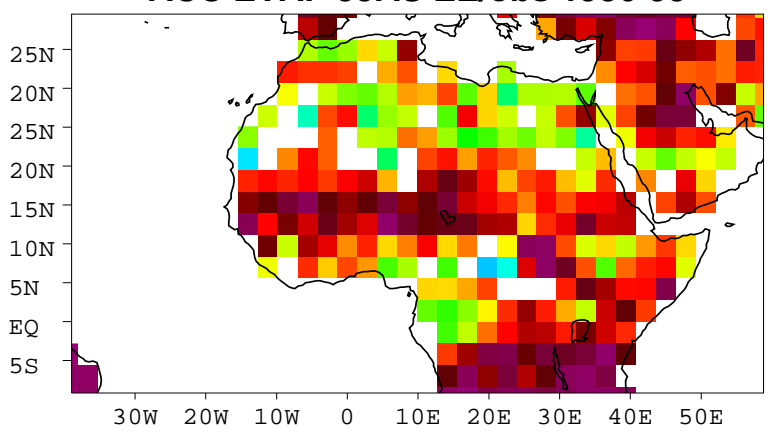

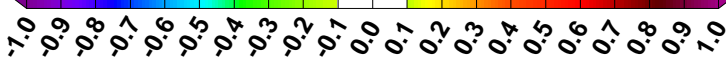

ACC PTOT JJAS FF/obs 1986-95
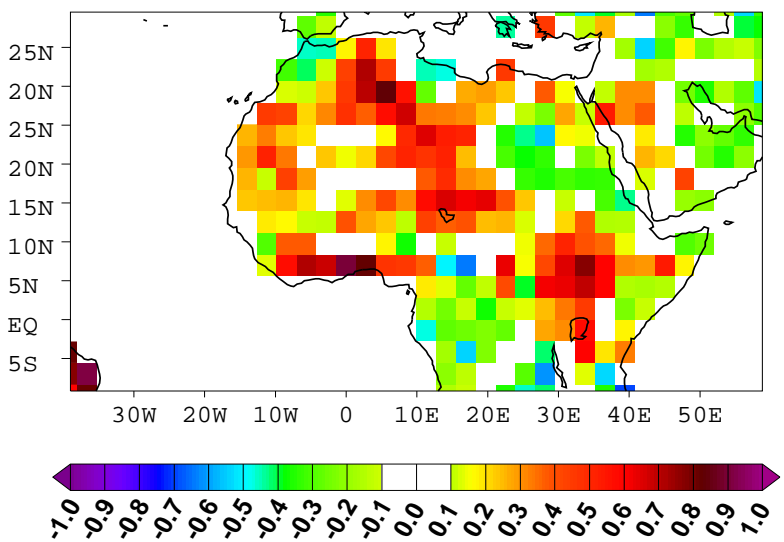

ACC PTOT JJAS GG/obs 1986-95

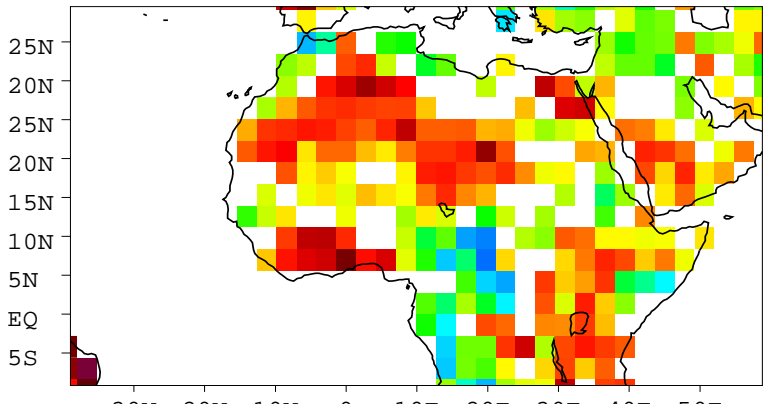

30W 20W 10W 0 10E 20E 30E $40 \mathrm{E} \quad 50 \mathrm{E}$

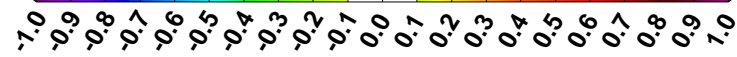

ACC PTOT JJAS EE/obs 1986-95
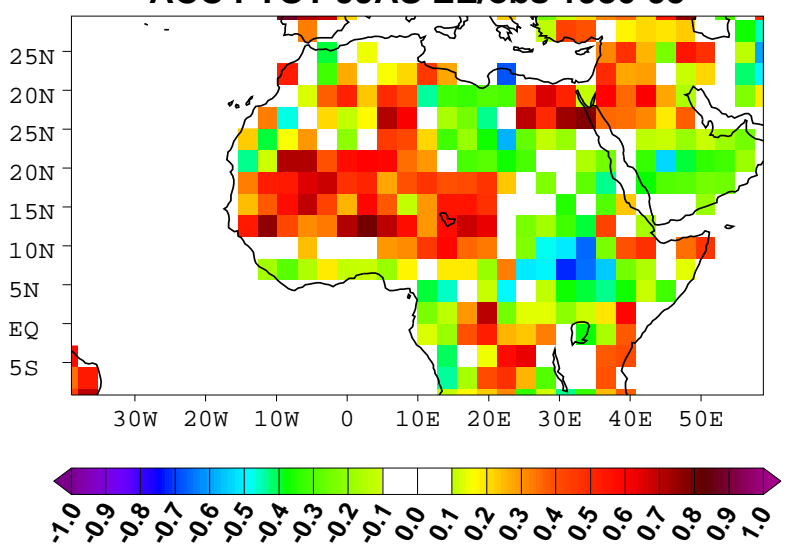

Figure 11: 


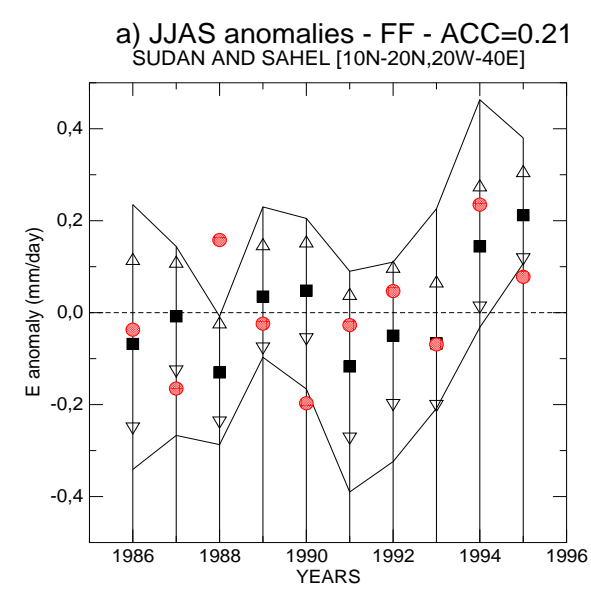

d) ASON anomalies - FF - ACC $=0.12$ SUDAN AND SAHEL [10N-20N,20W-40E]

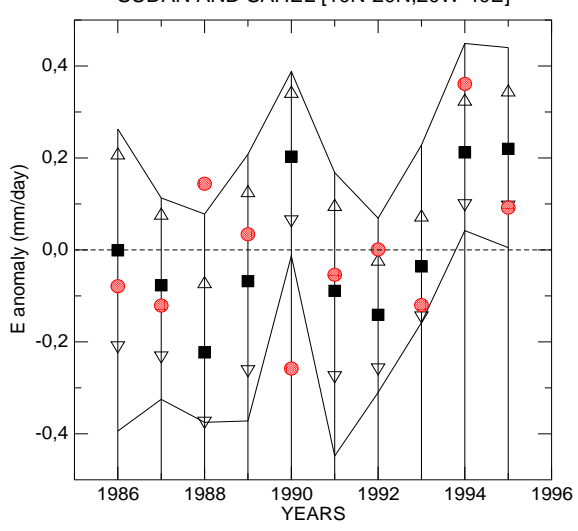

b) JJAS anomalies - GG - ACC $=0.55$

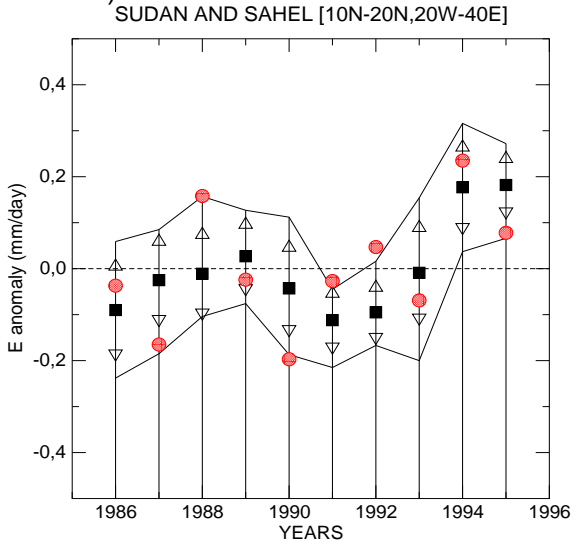

e) ASON anomalies - GG - ACC $=0.76$ SUDAN AND SAHEL [10N-20N,20W-40E]

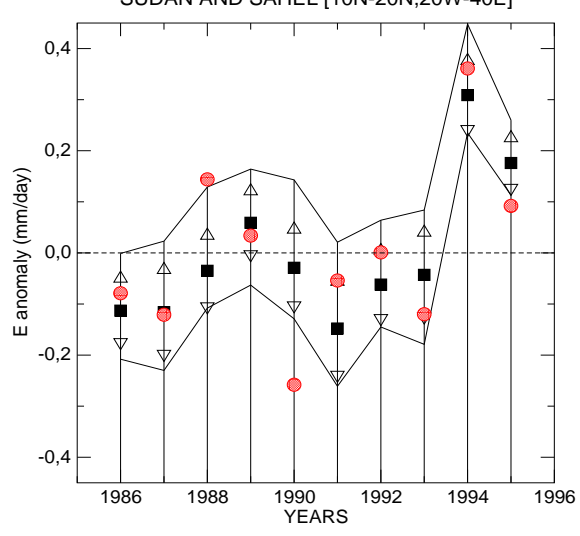

Figure 12:

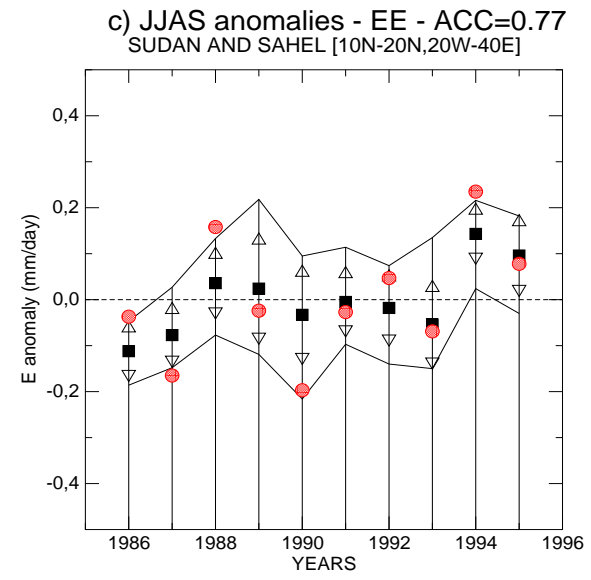

f) ASON anomalies - EE - ACC $=0.93$ SUDAN AND SAHEL [10N-20N,20W-40E]

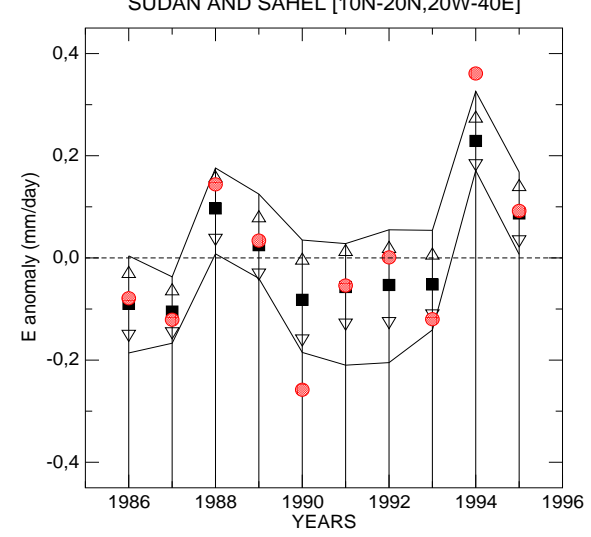




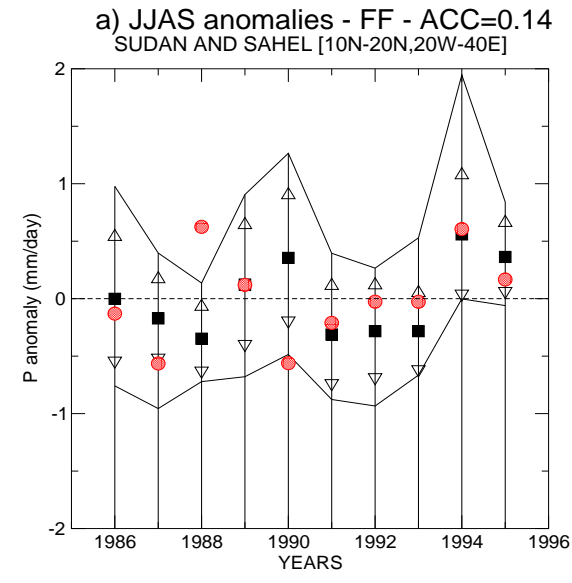

d) ASON anomalies - FF - ACC $=-0.05$ SUDAN AND SAHEL [10N-20N,20W-40E]

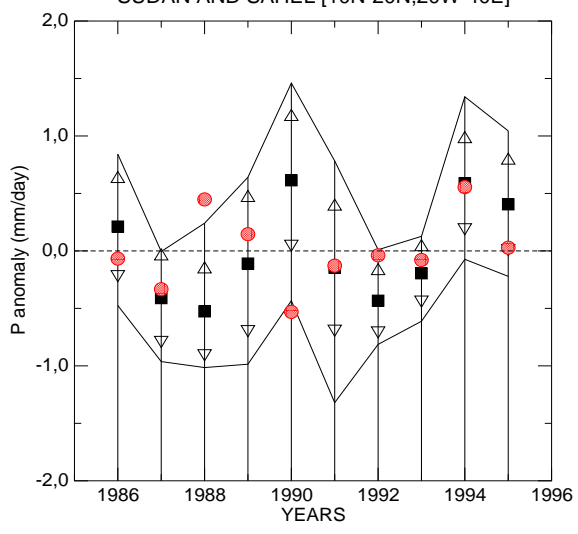

b) JJAS anomalies - GG - ACC $=0.01$ SUDAN AND SAHEL [10N-20N,20W-40E]

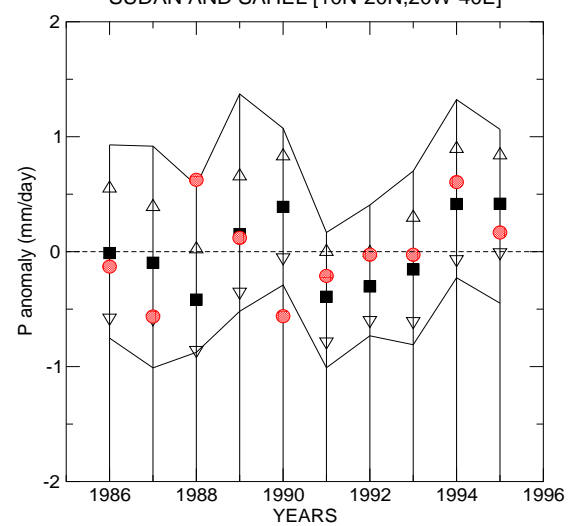

e) ASON anomalies - $\mathrm{GG}$ - ACC $=0.05$ SUDAN AND SAHEL [10N-20N,20W-40E]

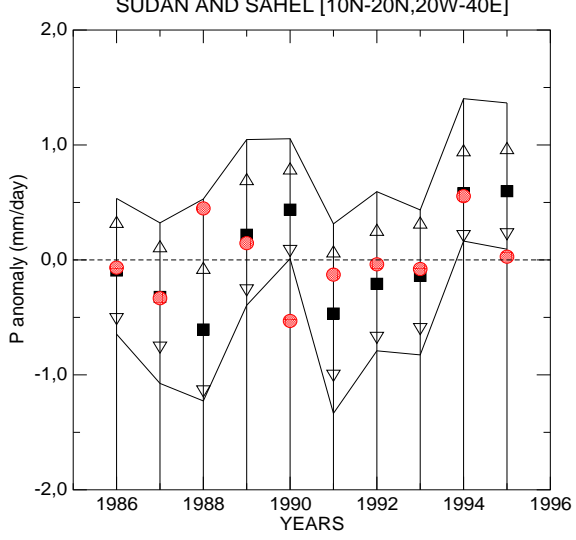

Figure 13: c) JJAS anomalies - EE - ACC $=0.48$ SUDAN AND SAHEL [10N-20N,20W-40E]

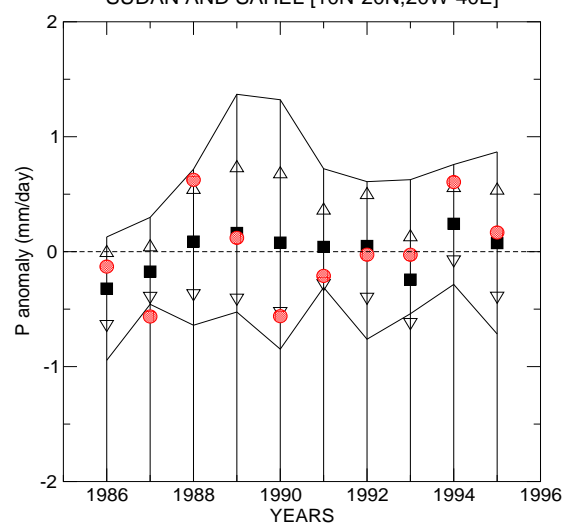

f) ASON anomalies - EE - $\mathrm{ACC}=0.73$ SUDAN AND SAHEL [10N-20N,20W-40E]

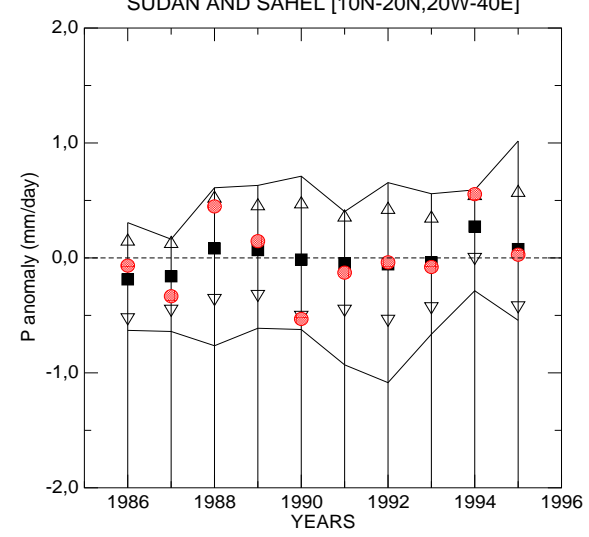



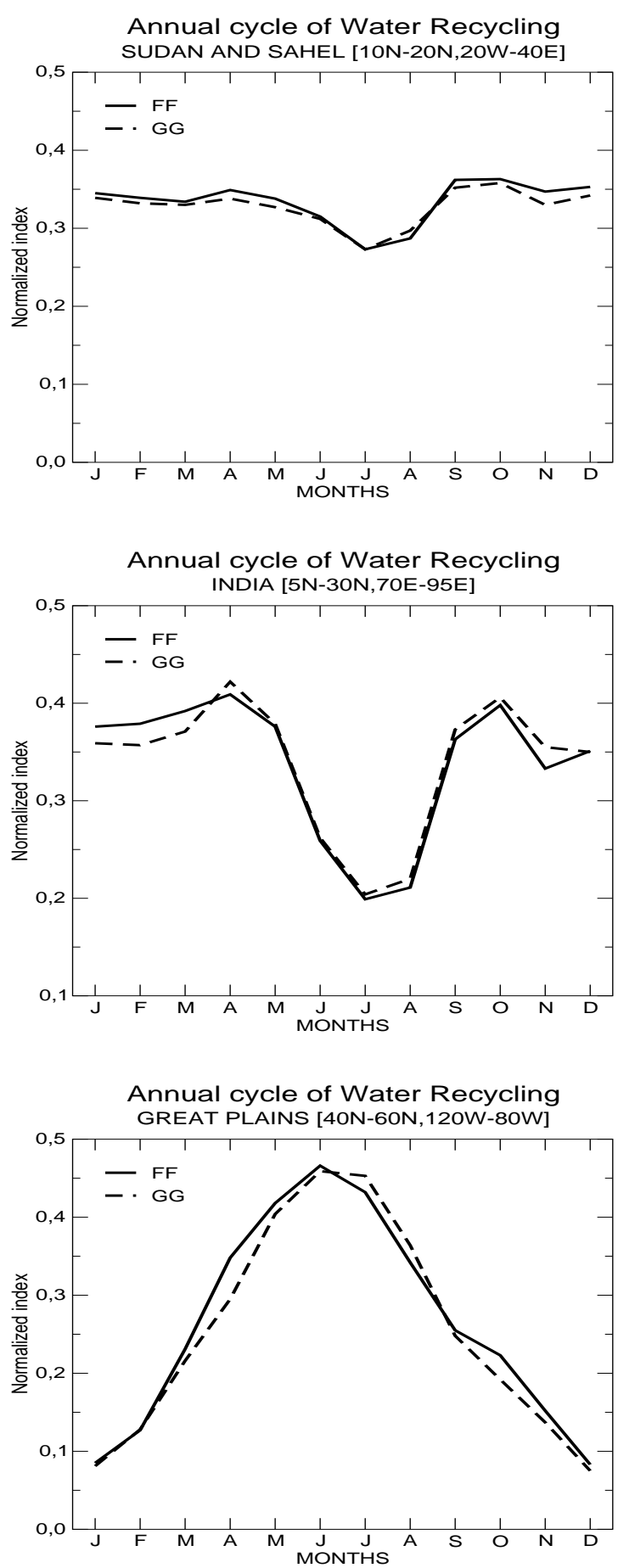

Figure 14: 


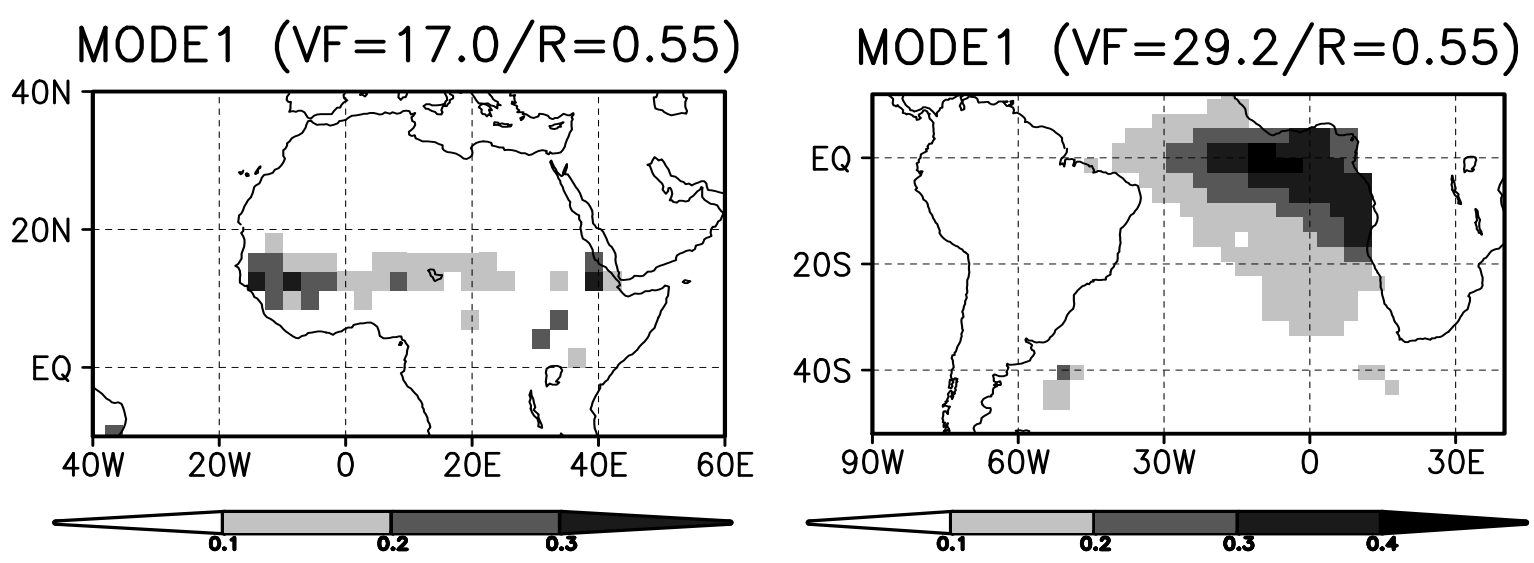

Figure 15: 


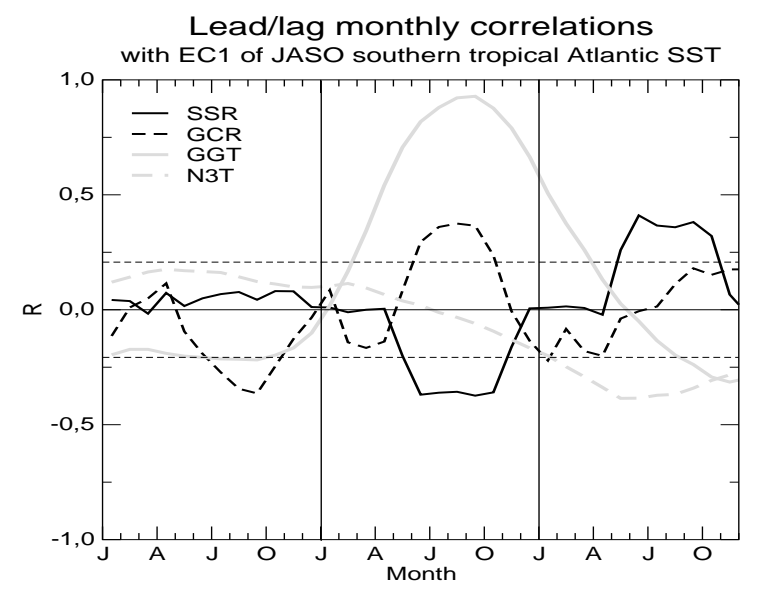

Figure 16: 